Article

\title{
In Vitro Anti-Candida Activity and Action Mode of Benzoxazole Derivatives
}

\author{
Monika Staniszewska ${ }^{1, *}$, tukasz Kuryk ${ }^{2,3}{ }^{\mathbb{D}}$, Aleksander Gryciuk ${ }^{4}$, Joanna Kawalec ${ }^{4} \mathbb{D}$, Marta Rogalska $^{4}$, \\ Joanna Baran 1,4 , Edyta Łukowska-Chojnacka 4 (D) and Anna Kowalkowska ${ }^{4, *}$
}

1 Centre for Advanced Materials and Technologies CEZAMAT, Warsaw University of Technology, Poleczki 19, 02-822 Warsaw, Poland; jbaran@ch.pw.edu.pl

2 Department of Virology, National Institute of Public Health-NIH-National Research Institute, Chocimska 24, 00-791 Warsaw, Poland; lkuryk@pzh.gov.pl

3 Clinical Science, Targovax Oy, Saukonpaadenranta 2, 00180 Helsinki, Finland

4 Faculty of Chemistry, Warsaw University of Technology, Noakowskiego St. 3, 00-664 Warsaw, Poland; alek.gryciuk@gmail.com (A.G.); joanna.kawalec.stud@pw.edu.pl (J.K.); martarogalska98@gazeta.pl (M.R.); elukowska@ch.pw.edu.pl (E.t.-C.)

* Correspondence: monika.staniszewska@pw.edu.pl (M.S.); anna.kowalkowska@pw.edu.pl (A.K.)

check for updates

Citation: Staniszewska, M.; Kuryk, Ł.; Gryciuk, A.; Kawalec, J.; Rogalska, M.; Baran, J.; Łukowska-Chojnacka, E.; Kowalkowska, A. In Vitro Anti-Candida Activity and Action Mode of Benzoxazole Derivatives. Molecules 2021, 26, 5008. https://doi.org/10.3390/ molecules 26165008

Academic Editor: Jean-Marc Sabatier

Received: 15 July 2021

Accepted: 12 August 2021

Published: 18 August 2021

Publisher's Note: MDPI stays neutral with regard to jurisdictional claims in published maps and institutional affiliations.

Copyright: (c) 2021 by the authors. Licensee MDPI, Basel, Switzerland. This article is an open access article distributed under the terms and conditions of the Creative Commons Attribution (CC BY) license (https:// creativecommons.org/licenses/by/ $4.0 /)$.

\begin{abstract}
A newly synthetized series of $N$-phenacyl derivatives of 2-mercaptobenzoxazole, including analogues of 5-bromo- and 5,7-dibromobenzoxazole, were screened against Candida strains and the action mechanism was evaluated. 2-(1,3-benzoxazol-2-ylsulfanyl)-1-(4-bromophenyl)ethanone (5d), 2-(1,3-benzoxazol-2-ylsulfanyl)-1-(2,3,4-trichloro-phenyl)ethanone (5i), 2-(1,3-benzoxazol-2ylsulfanyl)-1-(2,4,6-trichlorophenyl)ethanone (5k) and 2-[(5-bromo-1,3-benzoxazol-2-yl)sulfanyl]-1phenylethanone (6a) showed anti-C. albicans SC5314 activity, where $5 \mathbf{d}$ displayed $\mathrm{MIC}_{\mathrm{T}}=16 \mu \mathrm{g} / \mathrm{mL}$ $(\% \mathrm{R}=100)$ and a weak anti-proliferative activity against the clinical strains: $C$. albicans resistant to azoles (Itr and Flu) and C. glabrata. Derivatives 5k and 6a displayed MICP $=16 \mu \mathrm{g} / \mathrm{mL}$ and $\% \mathrm{R}=64.2 \pm 10.6, \% \mathrm{R}=88.0 \pm 9.7$, respectively, against the C. albicans isolate. Derivative $5 \mathbf{i}$ was the most active against C. glabrata $(\% \mathrm{R}=53.0 \pm 3.5$ at $16 \mu \mathrm{g} / \mathrm{mL})$. Benzoxazoles displayed no MIC against $C$. glabrata. Benzoxazoles showed a pleiotropic action mode: (1) the total sterols content was perturbed; (2) 2-(1,3-benzoxazol-2-ylsulfanyl)-1-(3,4-dichlorophenyl)ethanol and 2-(1,3-benzoxazol-2ylsulfanyl)-1-(2,3,4-trichlorophenyl)ethanol (8h-i) at the lowest fungistatic conc. inhibited the efflux of the Rho123 tracker during the membrane transport process; (3) mitochondrial respiration was affected/inhibited by the benzoxazoles: 2-(1,3-benzoxazol-2-ylsulfanyl)-1-(4-chlorophenyl)ethanol and 2-(1,3-benzoxazol-2-ylsulfanyl)-1-(4-bromophenyl)ethanol 8c-d and 8i. Benzoxazoles showed comparable activity to commercially available azoles due to (1) the interaction with exogenous ergosterol, (2) endogenous ergosterol synthesis blocking as well as (3) membrane permeabilizing properties typical of AmB. Benzoxazoles display a broad spectrum of anti-Candida activity and action mode towards the membrane without cross-resistance with AmB; furthermore, they are safe to mammals.
\end{abstract}

Keywords: benzoxazole; $N$-phenacyl; Candida spp.; action mode; in vitro

\section{Introduction}

Fungal diseases represent a critical worldwide health problem and they are one of the main causes of morbidity and mortality. Moreover, only a few classes of antifungals are currently available to treat patients with fungal infections due to their high toxicity [1] Therefore, it is still relevant to develop new alternative compounds, without harmful side-effects for patients, to prevent the emergence of fungal resistance. We, thus, undertook in vitro studies of anti-Candida's potential of new benzoxazoles. The benzoxazole ring is an important pharmacophore, that has for years been used to synthesize new biologically active compounds, including antifungal ones [2-8]. Among these compounds, there are 
derivatives of benzoxazoles active against Candida spp. [4-12]. Taking into account the structure of the compounds: 5-8, the confirmed activity of the 2-mercaptobenzoxazole derivatives against Candida spp. is particularly important $[13,14]$. On the other hand, the compounds $S$-functionalized with the phenacyl or halogen-phenacyl group also exhibit antifungal activity [14-20].

This prompted us to synthesize the $\mathrm{N}$-phenacyl derivatives of 2-mercaptobenzoxazole, including analogues of 5-bromo- and 5,7-dibromobenzoxazoles. The ketones were reduced to respective alcohols. In the study, we evaluated the toxicity of various benzoxazoles towards the mammalian cell lines as well as the fungistatic and fungicidal effect against the reference and clinical isolates resistant to azoles. The exogenous ergosterol affinity of the most active and randomly selected benzoxazoles was tested. Benzoxazoles inhibitory activity towards ergosterol synthesis was studied using the biochemical (high-performance liquid chromatography HPLC) and spectrophotometric method (SPE). Benzoxazole permeability/lytic activity against the fungal membrane was assessed via flow cytometry. Benzoxazoles exhibit the candidacidal mechanism via accidental cell death (ACD).

\section{Results}

\subsection{Synthesis of Benzoxazoles}

The synthesis of benzoxazole derivatives 5-8 is outlined in Schemes 1 and 2, as well as benzoxazoles summarized in Table 1. At first, 5-bromo-2-mercaptobenzoxazole 2 and 5,7-dibromo-2-mercaptobenzoxazole 3 were obtained according to procedures reported earlier [21] with the modification of one step. Instead of using a mixture of stannous chloride dihydrate and concentrated hydrochloric acid in a methanol reduction in the respective nitrophenols [21], it was carried out by $\mathrm{NaBH}_{4}$ in the presence of activated carbon in the THF- $\mathrm{H}_{2} \mathrm{O}$ mixture [22]. Ketones 5-7 were synthesized from 2-mercaptobenzoxazoles 1-3 and phenacyl bromides or chlorides 4 by $S$-alkylation carried out in the $\mathrm{K}_{2} \mathrm{CO}_{2} / \mathrm{MeCN}$ system (Scheme 1). Derivatives of 2-mercaptobenzoxazole 5 were easily obtained in high yields, while in the case of bromo-derivatives 6-7, more by-products were formed, so their yields were lower.<smiles>[R]c1cc([R])c2oc(S)nc2c1</smiles><smiles>[X]C(=O)CCCCC(C)C</smiles><smiles>[R]c1cc([R])c2oc(SCC(=O)Br)nc2c1</smiles>

1, $\mathrm{R}^{1}, \mathrm{R}^{2}=\mathrm{H}$ 4 2, $\mathrm{R}^{1}=\mathrm{Br}, \mathrm{R}^{2}=\mathrm{H} \quad \mathrm{X}=\mathrm{Cl}, \mathrm{Br}$ 3, $R^{1}, R^{2}=B r$
5, $R^{1}, R^{2}=H$
6, $\mathrm{R}^{1}=\mathrm{Br}, \mathrm{R}^{2}=\mathrm{H}$
7, $\mathrm{R}^{1}, \mathrm{R}^{2}=\mathrm{Br}$

Scheme 1. Synthesis of ketones 5-7 by S-alkylation of 2-mercaptobenzokxazoles 1-3.

$\mathrm{R}^{1}$<smiles>[R]c1cc(C)cc2nc(SCC(=O)[Al])oc12</smiles>

5, $\mathrm{R}^{1}, \mathrm{R}^{2}=\mathrm{H}$

6, $\mathrm{R}^{1}=\mathrm{Br}, \mathrm{R}^{2}=\mathrm{H}$

$7, R^{1}, R^{2}=B r$

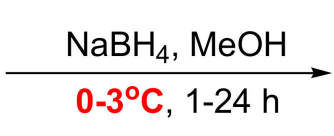<smiles>[Z1]c1cc([R])c2oc(SCC(O)[Al])nc2c1</smiles>

8, $R^{1}, R^{2}=H$

9, $\mathrm{R}^{1}=\mathrm{Br}, \mathrm{R}^{2}=\mathrm{H}$

10, $R^{1}, R^{2}=B r$

Scheme 2. Synthesis of alcohols 8 by reduction in ketones $5-7$.

Reduction in ketones 5 with $\mathrm{NaBH}_{4}$ in $\mathrm{MeOH}$ in room temperature afforded the mixture of products, alcohols 8 and respective 2-hydroxybenzoxazoles [23]. Decreasing 
of the reduction temperature to $0-3{ }^{\circ} \mathrm{C}$ allowed to obtain compounds 8 with moderate to good yields (Scheme 2). All alcohols 8 were isolated, but some of them turned out to be unstable not only at room temperature, but even when stored in the refrigerator (ca 3-5 ${ }^{\circ} \mathrm{C}$ ). Additionally, attempts to obtain respective alcohols, derivatives of bromobenzoxazoles 9 and 10, by the reduction in ketones 6 and 7 were rather unsuccessful, because of the formation of complicated mixtures of products. All alcohols 9 and 10, isolated in low yields and moderate purity, were unstable so they were not fully characterized and biologically tested.

All new stable compounds were fully characterized by ${ }^{1} \mathrm{H}$ NMR, ${ }^{13} \mathrm{C}$ NMR, IR and HRMS analyses.

Table 1. Yields of ketones 5, 6, 7 and alcohols 8 .

\begin{tabular}{ccccccc}
\hline Lp. & Benzoxazole & $\mathbf{4}, \mathbf{A r C O C H}_{\mathbf{2}} \mathbf{X}^{\mathbf{a}}$ & \multicolumn{2}{c}{ Ketone (\%) } & \multicolumn{2}{c}{ Alcohol (\%) } \\
\hline 1 & $\mathbf{1}$ & $\mathrm{C}_{6} \mathrm{H}_{5}$ & $\mathbf{5 a ~}[24-27]$ & 98 & $\mathbf{8 a}$ & $-{ }^{\mathrm{b}}$ \\
2 & $\mathbf{1}$ & $4-\mathrm{FC}_{6} \mathrm{H}_{4}$ & $\mathbf{5 b}$ & 91 & $\mathbf{8 b}$ & 88 \\
3 & $\mathbf{1}$ & $4-\mathrm{ClC}_{6} \mathrm{H}_{4}$ & $\mathbf{5 c}[24]$ & 95 & $\mathbf{8 c}$ & 91 \\
4 & $\mathbf{1}$ & $4-\mathrm{BrC}_{6} \mathrm{H}_{4}$ & $\mathbf{5 d ~ [ 2 4 , 2 7 ]}$ & 96 & $\mathbf{8 d}$ & 95 \\
5 & $\mathbf{1}$ & $2,4-\mathrm{F}_{2} \mathrm{C}_{6} \mathrm{H}_{3}$ & $\mathbf{5 e}$ & 88 & $\mathbf{8 e}$ & 57 \\
6 & $\mathbf{1}$ & $2,4-\mathrm{Cl}_{2} \mathrm{C}_{6} \mathrm{H}_{3}$ & $\mathbf{5 f}$ & 87 & $\mathbf{8 f}$ & 61 \\
7 & $\mathbf{1}$ & $2,5-\mathrm{Cl}_{2} \mathrm{C}_{6} \mathrm{H}_{3}$ & $\mathbf{5 g}$ & 91 & $\mathbf{8 g}$ & $377^{\mathrm{c}}$ \\
8 & $\mathbf{1}$ & $3,4-\mathrm{Cl}_{2} \mathrm{C}_{6} \mathrm{H}_{3}$ & $\mathbf{5 h}$ & 67 & $\mathbf{8 h}$ & 73 \\
9 & $\mathbf{1}$ & $2,3,4-\mathrm{Cl}_{3} \mathrm{C}_{6} \mathrm{H}_{2}$ & $\mathbf{5 i}$ & 92 & $\mathbf{8 i}$ & 87 \\
10 & $\mathbf{1}$ & $2,4,5-\mathrm{Cl}_{3} \mathrm{C}_{6} \mathrm{H}_{2}$ & $\mathbf{5 j}$ & 91 & $\mathbf{8 j}$ & 89 \\
11 & $\mathbf{1}$ & $2,4,6-\mathrm{Cl}_{3} \mathrm{C}_{6} \mathrm{H}_{2}$ & $\mathbf{5 k}$ & 64 & $\mathbf{8 k}$ & $-\mathrm{d}$ \\
12 & $\mathbf{2}$ & $\mathrm{C}_{6} \mathrm{H}_{5}$ & $\mathbf{6 a}$ & 71 & $\mathbf{9 a}$ & $39 \mathrm{c}, \mathbf{e}$ \\
13 & $\mathbf{2}$ & $4-\mathrm{FC}_{6} \mathrm{H}_{4}$ & $\mathbf{6 b}$ & 55 & $\mathbf{9 b}$ & $36^{\mathrm{c}, \mathrm{e}}$ \\
14 & $\mathbf{3}$ & $\mathrm{C}_{6} \mathrm{H}_{5}$ & $\mathbf{7 a}$ & 53 & $\mathbf{1 0 a}$ & $33^{\mathrm{c}, \mathrm{e}}$ \\
15 & $\mathbf{3}$ & $4-\mathrm{FC}_{6} \mathrm{H}_{4}$ & $\mathbf{7 b}$ & 39 & $\mathbf{1 0 b}$ & $-{ }^{\mathrm{e}}$
\end{tabular}

(a) Phenacyl bromide $\left(\mathrm{Ar}=\mathrm{C}_{6} \mathrm{H}_{5}, \mathrm{X}=\mathrm{Br}\right.$ ) and 4-chlorophenacyl bromide $\left(\mathrm{Ar}=4-\mathrm{ClC}_{6} \mathrm{H}_{4}, \mathrm{X}=\mathrm{Br}\right.$ ) were used; for all other compounds $4, \mathrm{X}=\mathrm{Cl}$. (b) Decomposition before purification. (c) Compound unstable. (d) Compound containing some by-products. (e) The mixture impossible to separate.

\subsection{Anti-Candida Activity of Benzoxazoles}

After the appropriate $48 \mathrm{~h}$ incubation time, the presence of growth was assessed visually and using the spectrophotometric method (SPE). Derivatives: $5 \mathbf{d}, \mathbf{5 i}$, $5 \mathbf{k}$ and $\mathbf{6 a}$ showed anti-C. albicans SC5314 ATCC activity (Tables 2, S1 and S2), where 5d displayed the total visual $\mathrm{MIC}_{\mathrm{T}}$ after $48 \mathrm{~h}$. Cell growth inhibition (SPE end-point \%R) and MIC were also determined (Tables 3, S3 and S4) against the Candida clinical isolates. Derivatives 5k or $6 \mathbf{a}$ at $16 \mu \mathrm{g} / \mathrm{mL}$ showed the $\mathrm{MIC}_{\mathrm{P}}$ partial values and, respectively, cell inhibition app. at $\%=64.2 \pm 10.6$ or $\%=88.0 \pm 9.7$ against the $C$. albicans isolates (Table 2$)$. Among the tested benzoxazoles, $5 \mathbf{i}$ was the most active at $16 \mu \mathrm{g} / \mathrm{mL}$ against C. glabrata $(\%=53.0 \pm 3.5$ in Table 3 and $\%=36.9 \pm 4.1$ in Table S4). Benzoxazole's MIC was not observed against the C. glabrata isolate.

Table 2. Antifungal activity of benzoxazole derivatives against C. albicans ATCC SC5314.

\begin{tabular}{|c|c|c|c|c|c|c|}
\hline \multirow{2}{*}{ Comp. } & \multicolumn{6}{|c|}{ Conc. $(\mu \mathrm{g} / \mathrm{mL})$} \\
\hline & 16 & 8 & 4 & 2 & 1 & 0.5 \\
\hline $5 \mathbf{a}$ & $11.7 \pm 3.8$ & $10.0 \pm 2.3$ & $10.4 \pm 4.7$ & $8.8 \pm 2.4$ & $8.1 \pm 0.6$ & $7.8 \pm 1.1$ \\
\hline $5 b$ & $99.3 \pm 4.3$ & $86.9 \pm 10.6$ & $80.3 \pm 13.4$ & $82.9 \pm 1.5$ & $72.0 \pm 21.9$ & $68.7 \pm 16.8$ \\
\hline $5 c$ & $96.4 \pm 0.6$ & $85.3 \pm 16.6$ & $85.7 \pm 16.6$ & $79.9 \pm 7.3$ & $79.4 \pm 4.3$ & $57.6 \pm 16.4$ \\
\hline $5 d$ & $100.3 \pm 3.2^{* *}$ & $96.4 \pm 2.6$ & $96.1 \pm 6.6$ & $76.5 \pm 10.0$ & $74.9 \pm 9.5$ & $71.0 \pm 15.0$ \\
\hline $5 e$ & $27.7 \pm 3.3$ & $10.9 \pm 2.9$ & $10.9 \pm 3.5$ & $10.0 \pm 2.5$ & $9.3 \pm 3.1$ & $7.2 \pm 0.1$ \\
\hline $5 f$ & $93.1 \pm 8.8^{*}$ & $87.6 \pm 2.2$ & $87.9 \pm 11.3$ & $82.1 \pm 2.6$ & $80.0 \pm 1.3$ & $68.2 \pm 20.3$ \\
\hline $5 g$ & $73.8 \pm 0.4$ & $72.9 \pm 0.6$ & $70.9 \pm 2.6$ & $71.8 \pm 5.1$ & $69.4 \pm 0.6$ & $68.8 \pm 0.6$ \\
\hline $5 h$ & $98.55 \pm 0.26$ & $98.52 \pm 0.20$ & $99.27 \pm 0.07$ & $98.99 \pm 0.15$ & $98.98 \pm 0.14$ & $98.33 \pm 0.26$ \\
\hline $5 \mathbf{i}$ & $78.7 \pm 2.1$ & $75.6 \pm 1.6$ & $73.3 \pm 2.7$ & $73.6 \pm 3.5$ & $73.3 \pm 20.2$ & $66.3 \pm 10.9$ \\
\hline
\end{tabular}


Table 2. Cont.

\begin{tabular}{|c|c|c|c|c|c|c|}
\hline \multirow{2}{*}{ Comp. } & \multicolumn{6}{|c|}{ Conc. $(\mu \mathrm{g} / \mathrm{mL})$} \\
\hline & 16 & 8 & 4 & 2 & 1 & 0.5 \\
\hline $5 i$ & $78.7 \pm 2.1$ & $75.6 \pm 1.6$ & $73.3 \pm 2.7$ & $73.6 \pm 3.5$ & $73.3 \pm 20.2$ & $66.3 \pm 10.9$ \\
\hline $5 \mathbf{j}$ & $17.6 \pm 0.8$ & $12.5 \pm 3.6$ & $9.1 \pm 0.6$ & $8.0 \pm 0.2$ & $8.1 \pm 0.5$ & $8.2 \pm 0.5$ \\
\hline $5 \mathrm{k}$ & $76.6 \pm 1.2^{*}$ & $74.5 \pm 1.7$ & $73.5 \pm 0.8$ & $72.5 \pm 27.0$ & $70.0 \pm 14.3$ & $65.8 \pm 10.2$ \\
\hline $6 a$ & $79.7 \pm 3.1 *$ & $74.9 \pm 1.2$ & $74.9 \pm 2.4$ & $72.8 \pm 15.2$ & $70.6 \pm 8.0$ & $70.7 \pm 0.2$ \\
\hline $6 b$ & $60.9 \pm 12.9$ & $45.0 \pm 8.3$ & $41.3 \pm 9.7$ & $30.8 \pm 7.2$ & $5.0 \pm 1.1$ & $2.0 \pm 1.1$ \\
\hline $7 \mathbf{a}$ & $79.5 \pm 12.5$ * & $45.0 \pm 16.1$ & $44.2 \pm 8.2$ & $42.0 \pm 20.1$ & $25.2 \pm 4.0$ & $17.7 \pm 3.1$ \\
\hline $7 \mathrm{~b}$ & $65.3 \pm 21.8$ & $39.7 \pm 9.3$ & $22.3 \pm 4.3$ & $31.6 \pm 17.6$ & $18.6 \pm 0.2$ & $5.0 \pm 1.1$ \\
\hline $8 b$ & $98.32 \pm 0.23$ & $98.47 \pm 0.21$ & $98.18 \pm 0.27$ & $98.84 \pm 0.18$ & $98.55 \pm 0.23$ & $98.59 \pm 0.16$ \\
\hline $8 c$ & $8.7 \pm 1.9$ & $8.8 \pm 1.9$ & $8.4 \pm 1.1$ & $7.5 \pm 0.5$ & $7.4 \pm 0.5$ & $6.9 \pm 0.0$ \\
\hline $8 d$ & $7.0 \pm 1.5$ & $6.5 \pm 0.6$ & $6.3 \pm 0.1$ & $6.4 \pm 0.1$ & $6.5 \pm 0.0$ & $6.4 \pm 0.0$ \\
\hline $8 e$ & $98.53 \pm 0.12$ & $99.43 \pm 0.07$ & $99.32 \pm 0.06$ & $98.78 \pm 0.10$ & $99.17 \pm 0.08$ & $99.24 \pm 0.10$ \\
\hline $8 f$ & $7.6 \pm 1.3$ & $6.8 \pm 0.3$ & $6.6 \pm 0.0$ & $6.9 \pm 0.2$ & $6.8 \pm 0.2$ & $6.6 \pm 0.0$ \\
\hline $8 h$ & $14.1 \pm 3.9$ & $8.1 \pm 0.2$ & $8.8 \pm 0.9$ & $8.7 \pm 0.5$ & $8.1 \pm 0.1$ & $7.8 \pm 0.1$ \\
\hline $8 \mathrm{i}$ & $10.9 \pm 4.7$ & $8.9 \pm 1.9$ & $7.1 \pm 0.1$ & $7.1 \pm 0.1$ & $6.8 \pm 0.0$ & $6.9 \pm 0.1$ \\
\hline $8 \mathbf{j}$ & $98.29 \pm 0.02$ & $99.28 \pm 0.16$ & $98.79 \pm 0.12$ & $98.38 \pm 0.22$ & $98.40 \pm 0.04$ & $98.41 \pm 0.20$ \\
\hline
\end{tabular}

Legend: Visual and spectrophotometric reading after $48 \mathrm{~h}$ of incubation: \% of growth inhibition at $405 \mathrm{~nm} ;{ }^{*}$ partial $\mathrm{MIC}_{\mathrm{P}} ;{ }^{* *}$ total $\mathrm{MIC}_{\mathrm{T}}$ were determined according to the CLSI method [28].

Table 3. Antifungal activity of $\mathbf{5 d}, 5 \mathbf{i}, 5 \mathbf{k}$ and $\mathbf{6 a}$ against the fungal isolates.

\begin{tabular}{|c|c|c|c|c|c|c|c|}
\hline \multirow{2}{*}{ Candida Isolate } & \multirow{2}{*}{ Comp. $(\mu g / m L)$} & \multicolumn{6}{|c|}{$\%$ Cell Growth Inhibition (Mean \pm SD) } \\
\hline & & 16 & 8 & 4 & 2 & 1 & 0.5 \\
\hline \multirow{4}{*}{ C. albicans } & $5 d$ & $52.0 \pm 15.7$ & $44.1 \pm 9.1$ & $40.6 \pm 14.9$ & $21.4 \pm 4.4$ & $20.4 \pm 10.3$ & $16.0 \pm 3.3$ \\
\hline & $5 \mathbf{i}$ & $55.7 \pm 13.1$ & $42.0 \pm 12.2$ & $22.9 \pm 12.2$ & $10.5 \pm 2.9$ & $6.5 \pm 2.9$ & $4.6 \pm 1.2$ \\
\hline & $5 \mathrm{k}$ & $\underset{*}{64.2 \pm 10.6}$ & $56.5 \pm 16.2$ & $44.4 \pm 14.3$ & $40.0 \pm 14.6$ & $1.7 \pm 0.4$ & $1.0 \pm 0.4$ \\
\hline & $6 \mathbf{a}$ & $88.0 \pm 9.7 *$ & $69.4 \pm 6.5$ & $48.0 \pm 6.6$ & $27.9 \pm 4.3$ & $26.5 \pm 9.3$ & $6.9 \pm 3.0$ \\
\hline \multirow{4}{*}{ C. glabrata } & $5 d$ & $38.3 \pm 3.8$ & $26.2 \pm 4.6$ & $16.6 \pm 4.2$ & $10.1 \pm 2.1$ & $14.5 \pm 1.0$ & $9.2 \pm 0.8$ \\
\hline & $5 \mathbf{i}$ & $53.0 \pm 3.5$ & $34.4 \pm 3.0$ & $14.4 \pm 2.8$ & $13.2 \pm 1.4$ & $11.6 \pm 2.1$ & $7.5 \pm 1.4$ \\
\hline & $5 k$ & $35.0 \pm 5.1$ & $19.1 \pm 1.7$ & $25.5 \pm 2.5$ & $26.5 \pm 3.4$ & $3.5 \pm 0.5$ & $12.3 \pm 1.4$ \\
\hline & $6 a$ & $27.0 \pm 6.1$ & $23.6 \pm 3.3$ & $10.4 \pm 1.3$ & $7.0 \pm 0.5$ & $3.0 \pm 0.5$ & $1.0 \pm 0.5$ \\
\hline
\end{tabular}

Legend: C. albicans (fluconazole- and itraconazole-resistant) and C. glabrata were isolated from patients with candidiasis; visual and spectrophotometric reading at $405 \mathrm{~nm}$ after $48 \mathrm{~h}$ incubation: * partial MIC in line with CLSI [28].

\subsection{Assessment of the Cytotoxicity against the Mammalian Cell Lines}

In the study, the primary cell lines suitable and routinely employed for the compound cytotoxic examination were tested [29,30]. These lines were temporarily available in our laboratory and they were chosen due to the most sensitive models used for assessing the toxicity of compounds $[29,30]$.

Among 5d, 6a and 7a tested against the Vero cells, a moderate cytotoxic effect $(\leq 63.8 \% \pm 8.7)$ was observed at $256 \mu \mathrm{g} / \mathrm{mL}$ (Table 4 and Table S5). In the case of these compounds, a weak or lack of cytotoxicity (app. at $18.4 \% \pm 0.4$ to $2.1 \pm 0.1$ ) at the conc. ranged from 128 to $1 \mu \mathrm{g} / \mathrm{mL}$ against Vero was noted. Derivatives $\mathbf{5 a}$ or $\mathbf{5 j}$ at $512 \mu \mathrm{g} / \mathrm{mL}$ showed a cytotoxicity, respectively, at $40.64 \% \pm 3.0$ or $50.75 \% \pm 0.0$. Contrariwise, $8 \mathbf{8 h}, \mathbf{8 c}, \mathbf{8 i}$ and $8 \mathbf{d}$ at the range of conc. starting from 512 to $128 \mu \mathrm{g} / \mathrm{mL}$ displayed a strong cytotoxicity $(84.38 \% \pm 0.1-63.26 \% \pm 0.3)$ against MRC-5 (Table 4 and Table S6). To sum up, the tested benzoxazoles at the antifungal concentrations showed a lack of cytotoxicity against the mammalian cells. 
Table 4. Cytotoxicity (mean $\% \pm$ SD) of benzoxazoles against the mammalian cell line.

\begin{tabular}{|c|c|c|c|c|c|c|c|c|c|c|c|}
\hline \multirow{2}{*}{ Cell Line ATCC } & \multirow{2}{*}{$\begin{array}{l}\text { Comp. } \\
{[\mu \mathrm{g} / \mathrm{mL}]}\end{array}$} & \multicolumn{10}{|c|}{$\%$ Cytotoxicity (Mean \pm SD) } \\
\hline & & 512 & 256 & 128 & 64 & 32 & 16 & 8 & 4 & 2 & 1 \\
\hline \multirow{3}{*}{ Kidney Vero E6 } & $5 d$ & - & $61.3 \pm 1.0$ & $18.4 \pm 0.4$ & $17.0 \pm 1.0$ & $8.7 \pm 0.2$ & $6.1 \pm 0.3$ & $4.4 \pm 0.2$ & $3.6 \pm 0.2$ & $3.4 \pm 0.1$ & $2.1 \pm 0.1$ \\
\hline & $6 a$ & - & $60.2 \pm 3.3$ & $17.2 \pm 0.4$ & $10.1 \pm 0.5$ & $5.4 \pm 0.3$ & $5.0 \pm 0.2$ & $2.9 \pm 0.1$ & $0.1 \pm 0.0$ & $0.0 \pm 0.0$ & $0.0 \pm 0.0$ \\
\hline & $7 a$ & - & $63.8 \pm 8.7$ & $14.4 \pm 0.5$ & $9.1 \pm 0.7$ & $5.4 \pm 0.4$ & $4.2 \pm 0.1$ & $1.6 \pm 0.1$ & $1.4 \pm 0.1$ & $0.9 \pm 0.0$ & $0.0 \pm 0.0$ \\
\hline \multirow{6}{*}{$\begin{array}{l}\text { Pulmonary Fibroblasts } \\
\text { MRC-5 }\end{array}$} & $5 a$ & $40.64 \pm 3.0$ & $39.03 \pm 3.2$ & $38.92 \pm 5.5$ & $38.69 \pm 2.3$ & $38.25 \pm 3.2$ & $36.67 \pm 3.0$ & $36.71 \pm 4.1$ & $36.15 \pm 2.7$ & $33.19 \pm 1.6$ & $32.59 \pm 0.8$ \\
\hline & $5 e$ & $13.98 \pm 0.7$ & $12.33 \pm 0.4$ & $9.97 \pm 0.6$ & $9.56 \pm 0.4$ & $9.22 \pm 0.5$ & $8.44 \pm 0.4$ & $8.10 \pm 0.5$ & $3.38 \pm 0.2$ & $2.59 \pm 0.2$ & $2.59 \pm 0.2$ \\
\hline & $5 \mathbf{j}$ & $50.75 \pm 0.0$ & $46.22 \pm 0.0$ & $45.02 \pm 0.0$ & $44.01 \pm 0.0$ & $40.19 \pm 0.1$ & $39.56 \pm 0.0$ & $38.92 \pm 0.1$ & $37.72 \pm 0.0$ & $35.81 \pm 0.0$ & $34.46 \pm 0.0$ \\
\hline & $8 d$ & $63.26 \pm 0.3$ & $83.54 \pm 0.0$ & $83.99 \pm 0.0$ & $22.09 \pm 0.0$ & $15.46 \pm 0.0$ & $13.21 \pm 0.0$ & $0.0 \pm 0.0$ & $12.37 \pm 0.0$ & $3.60 \pm 0.0$ & $6.75 \pm 0.0$ \\
\hline & $8 \mathrm{~h}$ & $81.13 \pm 0.0$ & $81.41 \pm 0.1$ & $81.97 \pm 0.0$ & $6.13 \pm 0.0$ & $0.0 \pm 0.0$ & $1.98 \pm 0.0$ & $1.86 \pm 0.0$ & $13.21 \pm 0.0$ & $7.82 \pm 0.0$ & $13.32 \pm 0.0$ \\
\hline & $8 \mathrm{i}$ & $71.24 \pm 0.2$ & $83.86 \pm 0.2$ & $83.00 \pm 0.0$ & $61.65 \pm 0.6$ & $17.65 \pm 0.0$ & $9.71 \pm 0.0$ & $11.51 \pm 0.0$ & $15.25 \pm 0.0$ & $11.39 \pm 0.0$ & $14.61 \pm 0$ \\
\hline
\end{tabular}

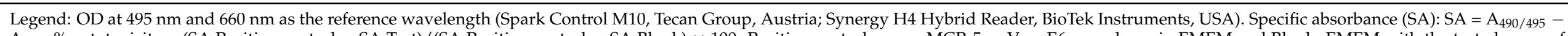

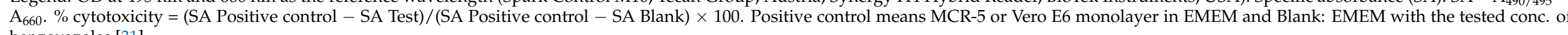
benzoxazoles [31]. 


\subsection{Estimation of the Ergosterol Content in the Benzoxazole-Treated Candida Blastoconidia}

The results of the spectrophotometric (SPE) analyses showed a conc.-dependent decrease in the ergosterol content when the C. albicans ref. strain was grown, respectively, at conc. of 16 or $4 \mu \mathrm{g} / \mathrm{mL}$ of $\mathbf{5 d}$ (Table 5). In comparison to the untreated control, the mean of the total ergosterol content in the $5 \mathrm{~d}$-treated C. albicans ref. strain decreased app. by 1.3 -fold at $16 \mu \mathrm{g} / \mathrm{mL}$ and 1.2 -fold at $4 \mu \mathrm{g} / \mathrm{mL}$. Derivative $5 \mathrm{~d}$ displayed the reverse action mode against the C. albicans isolate, e.g., 1.3 -fold at $16 \mu \mathrm{g} / \mathrm{mL}$ and 1.7 -fold increase at $4 \mu \mathrm{g} / \mathrm{mL}$. Exposure of the ref. cells to $6 \mathbf{a}$ or $7 \mathbf{a}$ generated a higher ergosterol content at $16 \mu \mathrm{g} / \mathrm{mL}$ with a mean decrease in the total of its content, app. by one-fold (6a and $7 \mathbf{a}$ ) for the ref. strain vs. the untreated control. The $\mathbf{6 a}$ - or $7 \mathbf{a}$-treated clinical isolate displayed the mean decrease app. by 1 -fold (6a and $7 \mathbf{a}$ ) at conc. of $16 \mu \mathrm{g} / \mathrm{mL}$ and by 1.5 -fold at $4 \mu \mathrm{g} / \mathrm{mL}$, compared to the untreated control. Using the SPE analyses, we showed that the differences in the ergosterol content between the benzoxazole-treated vs. untreated control were statistically significant $(p=0.003)$.

Table 5. UV spectrometric ergosterol content (\%) in the benzoxazole-treated C. albicans.

\begin{tabular}{ccccc}
\hline \multirow{2}{*}{ Candida albicans } & \multicolumn{4}{c}{ Ergosterol Content $(\mathbf{\%} \pm \mathbf{S D})$} \\
\cline { 2 - 5 } & Comp. $(\boldsymbol{\mu g} / \mathbf{m L})$ & $\mathbf{5 d}$ & $\mathbf{6 a}$ & $\mathbf{7 a}$ \\
\hline \multirow{2}{*}{ ATCC SC5314 } & $\mathbf{1 6}$ & $73.8 \pm 3.2$ & $93.9 \pm 4.3$ & $95.5 \pm 3.7$ \\
& $\mathbf{4}$ & $79.8 \pm 3.2$ & $57.3 \pm 1.6$ & $84.2 \pm 3.8$ \\
\hline \multirow{2}{*}{ Clinical isolate } & $\mathbf{1 6}$ & $74.3 \pm 3.5$ & $83.4 \pm 4.1$ & $99.9 \pm 5.0$ \\
& $\mathbf{4}$ & $57.8 \pm 2.7$ & $66.1 \pm 4.3$ & $68.0 \pm 2.0$ \\
\hline
\end{tabular}

Legend: The data are compared to the untreated control. * Percentage of the cell pellet wet weight (mean \pm SD) C. albicans (fluconazole- and itraconazole-resistant).

Moreover, the ergosterol content was measured using HPLC (Tables 6 and S7). Interestingly, when applying $5 \mathbf{d}$ at $16 \mu \mathrm{g} / \mathrm{mL}\left(\mathrm{MIC}_{\mathrm{T}}\right)$, the treatment favoured the increase in the ergosterol content app. by 0.9 -fold vs. the untreated control, while $4 \mu \mathrm{g} / \mathrm{mL}$ inhibited the ergosterol content app. by 1.3-fold vs. the control (Table 6). Contrariwise, we observed a 1.5- or 1.3-fold-decreased ergosterol content, respectively, for $6 \mathbf{a}$ or $7 \mathbf{a}$ at $16 \mu \mathrm{g} / \mathrm{mL}$ vs. the untreated control. The content of ergosterol in the ref. strain was reduced in the range of 1.2-1.5-fold for all the tested compounds at $4 \mu \mathrm{g} / \mathrm{mL}$. In the case of the clinical isolate, $7 \mathbf{a}$ at conc. of $16 \mu \mathrm{g} / \mathrm{mL}$ induced 0.9 -fold higher ergosterol vs. the untreated control. On the contrary, $\mathbf{5 d}$ or $\mathbf{6 a}$ at $16 \mu \mathrm{g} / \mathrm{mL}$ reduced the ergosterol content by 1.9 - or 3-fold, respectively, vs. the untreated control. These compounds at $4 \mu \mathrm{g} / \mathrm{mL}$ reduced the content of ergosterol by the following levels: 1-fold (5d), 2-fold (6a) or 1.4 (7a). Using HPLC, we showed the statistically significant differences in the ergosterol content between the benzoxazole-treated and the untreated control $(p=0.007)$.

Table 6. Ergosterol quantification in the benzoxazole-treated C. albicans using HPLC.

\begin{tabular}{ccccc}
\hline \multirow{2}{*}{ Candida albicans } & \multirow{2}{*}{ Comp. $(\boldsymbol{\mu g} / \mathrm{mL})$} & \multicolumn{3}{c}{ Ergosterol Conc. (\% $\pm \mathbf{S D})$} \\
\cline { 3 - 5 } & & $\mathbf{5 d}$ & $\mathbf{6 a}$ & $\mathbf{7 a}$ \\
\hline \multirow{2}{*}{ ATCC SC5314 } & $\mathbf{1 6}$ & $114.4 \pm 9.2$ & $65.9 \pm 5.3$ & $72.7 \pm 5.8$ \\
& $\mathbf{4}$ & $78.0 \pm 6.2$ & $67.9 \pm 5.4$ & $63.2 \pm 3.8$ \\
\hline \multirow{2}{*}{ Clinical isolate } & $\mathbf{1 6}$ & $51.7 \pm 4.1$ & $33.1 \pm 2.6$ & $112.4 \pm 9.0$ \\
& $\mathbf{4}$ & $97.3 \pm 7.8$ & $52.6 \pm 4.2$ & $71.6 \pm 5.7$ \\
\hline
\end{tabular}

Legend: Data are compared to the untreated control. HPLC analysis was performed using 200 Series Nelson NCI 900 system with UV/VIS detection at $282 \mathrm{~nm}$ (PerkinElmer, Waltham, USA) and COSMOSIL C18-MS-II column (nacalai tesque, Kyoto, Japan). Gradient elusion was performed starting with acetonitrile; methanol 97:3 $v / v$ as the mobile phase. The $C$. albicans clinical isolate fluconazole- and itraconazole-resistant was used.

Based on the method comparison studies (Regression and Pearson correlation coefficient), it was shown that there was a large bias in these two methods used to assess the 
ergosterol content. The Pearson correlation coefficient $(\mathrm{r}=0.5)$ and $p=0.12$ indicated a moderate correlation between these two methods. The SPE method produced slightly more accruable results due to the smaller $p$-value. In spite of this, there was $p<0.05$ for these two methods; thus, both were worth applying.

\subsection{Cell Death Assessment Using Flow Cytometry}

To assess the ability of the benzoxazole derivatives to induce accidental cell death (ACD) in C. albicans, the blastoconidial cells were treated with compounds at $16 \mu \mathrm{g} / \mathrm{mL}$ (Figure 1) or $4 \mu \mathrm{g} / \mathrm{mL}$ (Table S8) and \% of the cell death was assessed by the appearance of propidium iodide (PI) staining using flow cytometry. We found that the treatment of the cells with benzoxazoles led to an irreversible plasma membrane breakdown (app. $\sim 99.52 \%$ ) vs. the untreated blastoconidial control (99.77\%). Additionally, benzoxazoles at 16 or $4 \mu \mathrm{g} / \mathrm{mL}$ induced necrosis in the $C$. albicans protoplasts.

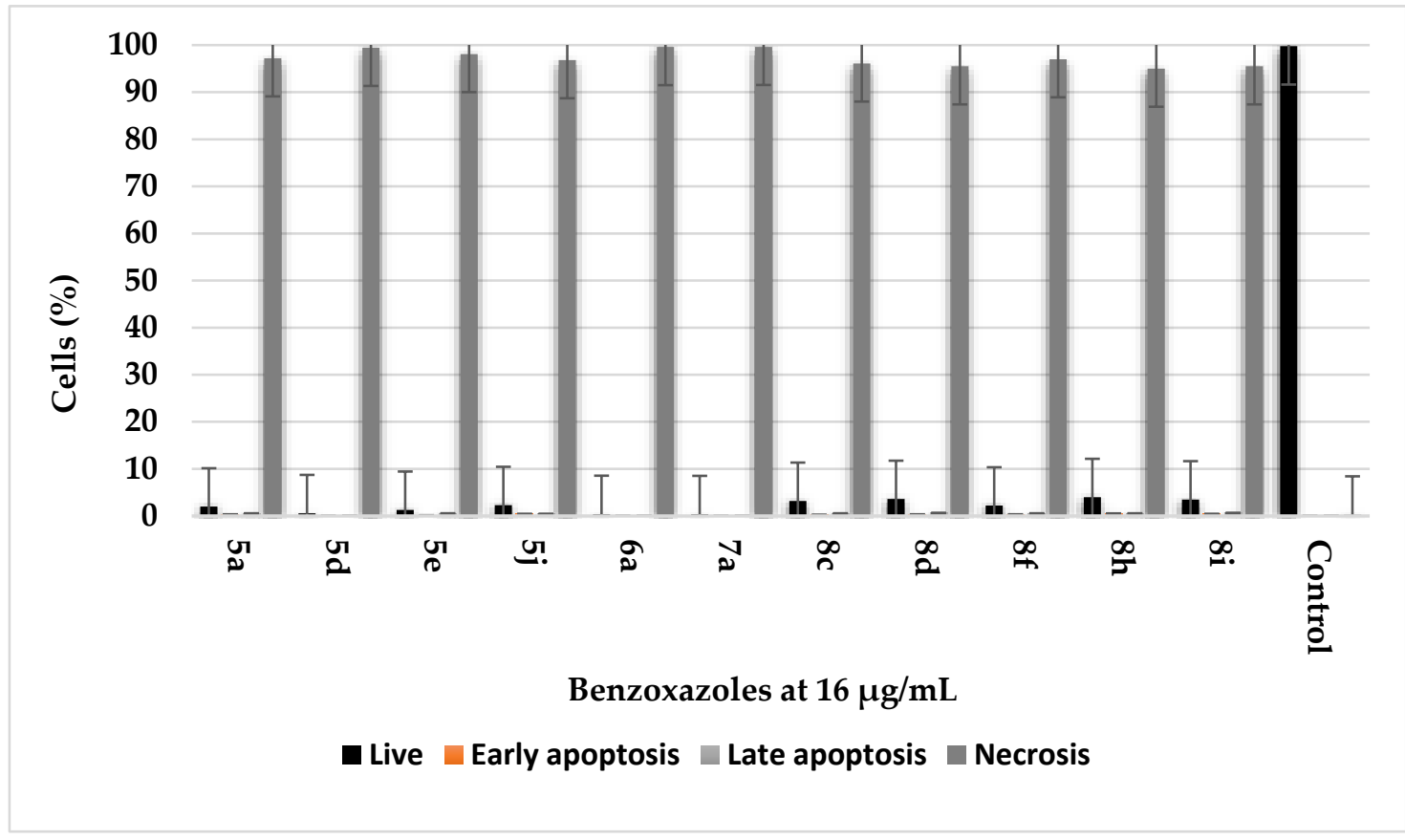

Figure 1. Accidental cell death of C. albicans generated by benzoxazoles. Legend: PI means propidium iodide, PI intercalating strategy to characterize accidental cell death (ACD), \% PI-Positivity means \% cell death assessed during automated readout using flow cytometry BD FACSLyric 2L6C (BD Biosciences. USA).

\subsection{Efflux Study in the Benzoxazole-Treated C. albicans Cells}

The least active fungistatic compounds were tested for the Rho123 efflux at the highest $(160$ or $16 \mu \mathrm{g} / \mathrm{mL}$ ) or the lowest $(1.25$ or $0.125 \mu \mathrm{g} / \mathrm{mL}$ ) antifungal conc. tested (Figure 2, Table S9). The SPE reading revealed that $5 \mathbf{j}$ and $\mathbf{8 h}$ at $0.125 \mu \mathrm{g} / \mathrm{mL}$ as well as $\mathbf{5 a}$ and $\mathbf{5 e}$ at $16 \mu \mathrm{g} / \mathrm{mL}$ increased the efflux vs. the untreated control $\left(\mathrm{OD}_{600 \mathrm{~nm}}=3901\right)$. Generally, the fungistatic compounds tested at lower conc. induced the cell efflux activity. In details, when all compounds at two different conc. were tested, there were differences in the efflux as follows: $\mathbf{5 j}$ (1-fold increase in the efflux at the lowest conc. tested vs. the highest one); $\mathbf{8 d}$ (1.2-fold); $5 \mathbf{a}$ and $8 \mathbf{c}$ (1.6-fold); $5 \mathbf{e}$ (1.7-fold). On the contrary, $8 \mathbf{i}$ caused a decrease in the efflux (4.6-fold) at the lowest conc. tested vs. the highest one. Although all benzoxazoles exhibited a comparable fungistatic effect, they showed a diversity in the cell efflux inhibition. Derivatives: 8c, $\mathbf{8 i}$ and $\mathbf{8 d}$ inhibited the blastoconidial efflux. The Rho123 efflux in the benzoxazole-treated SC5314 was stimulated by the glucose addition, but since it gradually decreased along with the increasing concentration of $\mathbf{8 d}$, this derivative was taken as an illustrative example. 


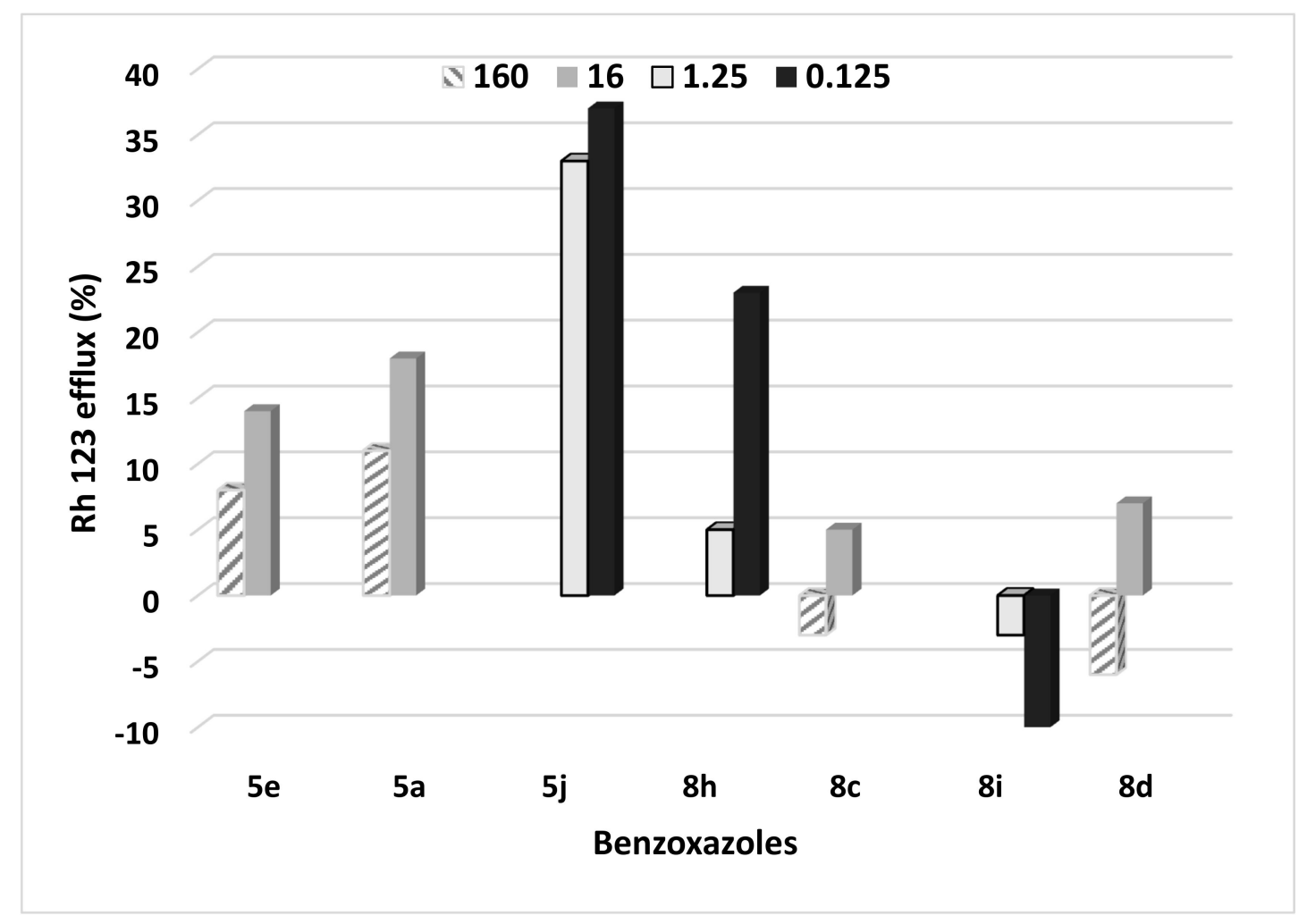

Figure 2. Benzoxazoles' influence on the passive efflux of Rho123. Legend: Rhodamine (Rho123) content as a relative difference between the control and test (\%) in the post-culture medium of the C. albicans SC5314 treated with compounds 5a, $\mathbf{5 e}, \mathbf{5 j}, \mathbf{8 c}, \mathbf{8 h}, \mathbf{8 i}$ and $\mathbf{1 3 d}$ at different concentrations. $\% \mathrm{C}=(\mathrm{A}($ test $)-\mathrm{A}($ control $)) / \mathrm{A}($ control $) \times 100$, where $\mathrm{A}($ control $)=3901$. The C. albicans cells were incubated with Rho123 at $20 \mathrm{mM}$ for $10 \mathrm{~min}$ and the Rho123 extracellular conc. was determined against a standard curve following the cell lysis with Triton 6100. Standard curve: $A=1155.9 C+3901 \rightarrow C=\frac{A-3901}{1155.9}$. Data mean the average of three separate repeats S.D.

\subsection{Determination of Antifungal Activity of Benzoxazole Derivatives in the Presence of Exogenous Ergosterol}

To address whether exogenous ergosterol could relieve benzoxazole stress in C. albicans, blastoconidia at $\log$ phase were harvested and then treated with benzoxazoles at various concentrations in a medium containing ergosterol at $20 \mathrm{mM}$ (Figures 3 and S1). The itraconazole-treated blastoconidia in the medium supplemented with ergosterol and blastoconidia growing in the medium containing ergosterol were used as the controls. After $96 \mathrm{~h}$ of $\mathbf{8 d}$ or $\mathbf{8 f}$ treatment, the blastoconidial cell survival slightly decreased at the highest concentrations of compounds. The activity of $\mathbf{8 d}$ and $\mathbf{8 f}$ was comparable to Itr. Thus, the results were consistent with the antifungal activity of Itr, showing that exogenous ergosterol reduced the $C$. albicans tolerance to $\mathbf{8} \mathbf{d}$ and $\mathbf{8 f}$. Differences in the antifungal effect between Itr and $\mathbf{5 e}$ as well as Itr vs. $8 \mathrm{~h}$ were noted.

As it was shown in Figure S1, benzoxazoles $5 \mathbf{a}, \mathbf{5 j}, \mathbf{8 c}$ and $\mathbf{8 i}$ displayed no interaction with ergosterol as the curves differed from the Itr action. The curves of $\mathbf{5 a}, \mathbf{5 j}, \mathbf{8 c}$ and $\mathbf{8 i}$ differed from Itr vs. the growth control curves. 

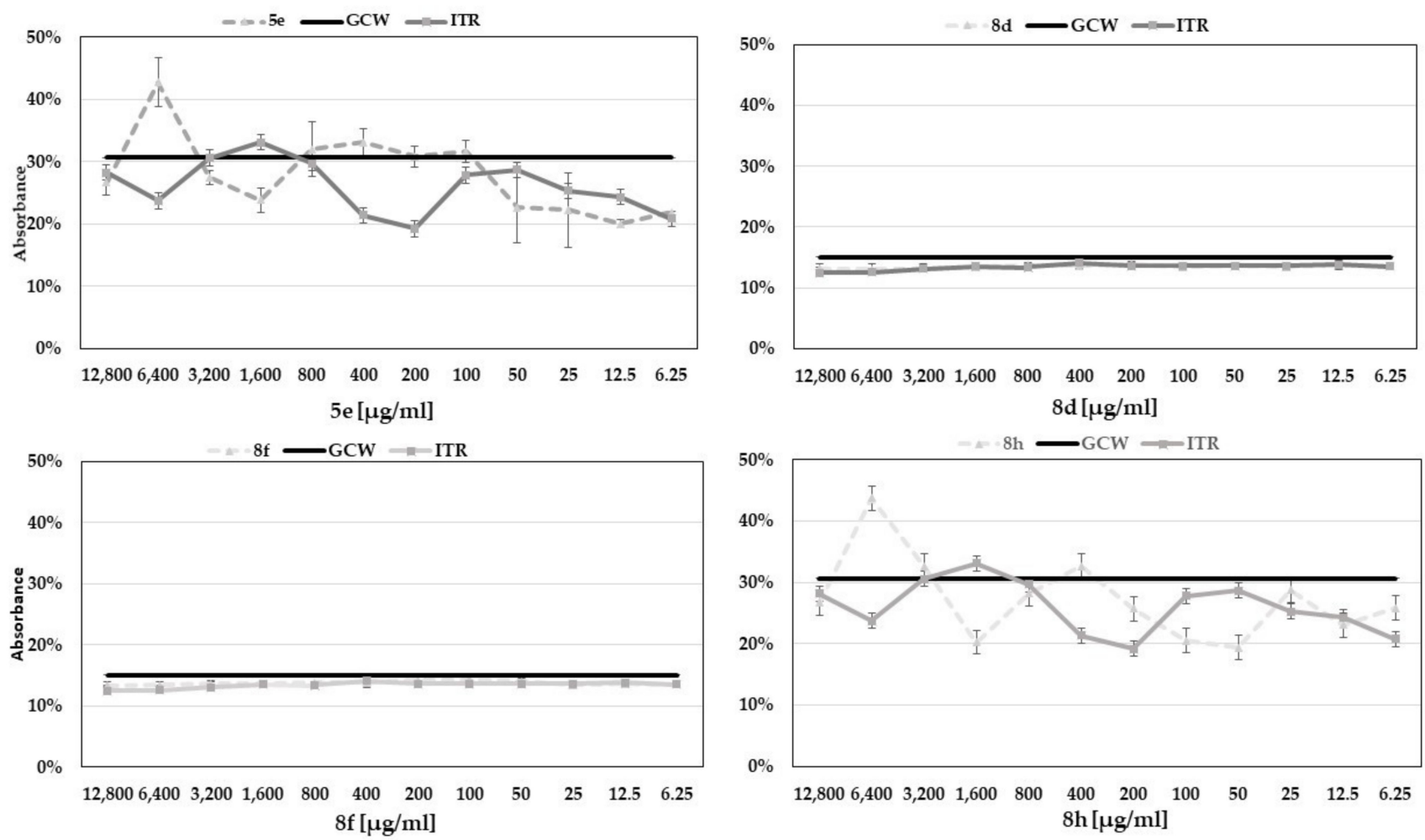

Figure 3. The interaction between benzoxazoles and exogenous ergosterols. Legend: Absorbance at $400 \mathrm{~nm}$ after $96 \mathrm{~h}$ incubation of the C. albicans SC5314 cells in YEPD containing different concentrations of benzoxazoles and exogenous ergosterol. The mean \% of absorbance of the growth control is presented as GCW. ITR means Itraconazole. The assay was performed in triplicate. Values are presented as means $\pm \mathrm{SD}$.

2.8. Anti-Candida Effect of Benzoxazole Derivatives Combined with Amphotericin B (AmB). FIC Index Calculation

As it was shown in Table 7, we summarized the combined activities of $\mathbf{5 d}$ with amphotericin $(\mathrm{AmB})$ in the in vitro checkboard interactions against $C$. glabrata. The FIC index interpretations for the activities of $\mathbf{5 d}$ with $\mathrm{AmB}$ against $C$. glabrata recorded an indifference for all combinations. Synergism or antagonism were not recorded for any combinations.

Table 7. FIC indexes of $\mathbf{5 d}$ combined with AmB against C. glabrata.

\begin{tabular}{cccc}
\hline \multirow{2}{*}{ Comp. } & MIC $(\mu \mathrm{g} / \mathrm{mL})$ & & Outcomes \\
\cline { 2 - 4 } & Alone & Combination & No rules \\
& & 16 & 2.5 \\
& & 2 & 1.25 \\
& & 2 & Indifference \\
& $4^{*}$ & 2.5 & 1 \\
& $1.25^{* *}$ & 2.5 & 0.5 \\
& & 2.25 & 0.25 \\
\end{tabular}

Legend: * partial inhibition: $\mathrm{MIC}_{\mathrm{p}}$; ${ }^{* *}$ total inhibition: $\mathrm{MIC}_{\mathrm{T}}$. AmB means amphotericin B (stock conc.: $250 \mu \mathrm{g} / \mathrm{mL}$ ), $\Sigma \mathrm{FIC}=\mathrm{C}(\mathbf{5 d}) / \mathrm{MIC}_{\mathrm{P}}(\mathbf{5 d})+\mathrm{C}(\mathrm{AmB}) / \mathrm{MIC}_{\mathrm{T}}(\mathrm{AmB}) ; \mathbf{C}$ means conc. of $\mathbf{5 d}$ or AmB in well containing combination of two compounds, resulting in $100 \%$ growth inhibition in the spectrophotometric (SPE) method at $405 \mathrm{~nm}$. $\Sigma$ FIC for $\mathbf{5 d}$ and AmB against C. glabrata and incubation time of $96 \mathrm{~h}$. Interactions were categorized according to the method of Te Dorsthorst et al. [32] by the following rules: synergism (FIC $\leq 0.5$ ), additivity (FIC $>0.5$ to $\leq 1$ ) and indifference (FIC $>1$ to $<4$ ). 


\section{Discussion}

The library of 23 benzoxazoles featuring 2-mercaptobenzoxazole with the phenacyl moiety or respective alcohols was screened for the anti-Candida activity (Tables 2, 3 and S1-S4). The active derivatives $\mathbf{5 d}, \mathbf{5 i}, \mathbf{5 k}$ and $\mathbf{6 a}\left(\mathrm{MIC}_{\mathrm{T} / \mathrm{P}}=16 \mu \mathrm{g} / \mathrm{mL}\right)$ were tested against the C. albicans clinical isolates (resistant to Flu and Itr) and C. glabrata displaying an intrinsically decreased susceptibility to azoles [33]. 2,4,6-Trichlorophenacyl- (5k) or 5-bromobenzoxazole (6a) derivatives showed modest activity (spectrophotometric SPE end-point of $\% \mathrm{R}=64.2 \pm 10.6$ and $\% \mathrm{R}=88.0 \pm 9.7$ at $16 \mu \mathrm{g} / \mathrm{mL}$ ) against the $C$. albicans clinical strain, respectively. The 2,3,4-trichlorophenacyl derivative (5i) exerted the most potent anti-C. glabrata action $(\% \mathrm{R}=53.0 \pm 3.5$ at $16 \mu \mathrm{g} / \mathrm{mL})$. In spite of the total $\mathrm{MIC}_{\mathrm{T}}=16 \mu \mathrm{g} / \mathrm{mL}(\% \mathrm{R}=100.3 \pm 3.2)$ against the reference strain, $5 \mathrm{~d}$ functionalized with the 4-bromophenacyl group displaying low activity against both azole-resistant isolates (Table 3). The structure activity relationship clearly indicated that the bromo- or chlorosubstituted 2-mercaptobenzoxazole with the phenacyl moiety showed activity against the Candida reference and clinical azole-resistant strains. Contrary to the literature data [34], the fluoro derivatives were not among the most active compounds. It was evident from the results (Tables 4, S5 and S6) that all benzoxazoles at $128 \mu \mathrm{g} / \mathrm{mL}$ displayed more than $81.6 \% \pm 1.8$ of the Vero cell viability. The MRC- 5 cells showed a viability of app. $\geq 18.9 \%$ when treated with $\mathbf{8 h}$ or $\mathbf{8 c}-\mathbf{d}, \mathbf{8} \mathbf{i}$ at $512 \mu \mathrm{g} / \mathrm{mL}$, as well as a $\geq 50.0 \%$ cell viability when treated with $\mathbf{5 a}, \mathbf{5 e}$ or $\mathbf{5 j}$.

We tested the capacity of benzoxazoles to inhibit the ergosterol synthesis (Tables 5 and 6). The results showed $\mathbf{5 d}$ 's conc. dependent decrease in the ergosterol content when the $C$. albicans ref. strain was grown, respectively, at conc. of 16 or $4 \mu \mathrm{g} / \mathrm{mL}$. In comparison to the untreated control, the mean of the total ergosterol content decreased in the $5 \mathrm{~d}$-treated C. albicans ref. (1.3-fold at $16 \mu \mathrm{g} / \mathrm{mL}$ and 1.2 -fold at $4 \mu \mathrm{g} / \mathrm{mL}$ ). The above was consistent with the cell proliferation inhibition data (in Tables 2, S1 and S2), where MIC's $\mathbf{5 d}$ against SC5314 was the total and \% $\mathrm{R}=100$ was noted. Contrariwise, $\mathbf{5 d}$ displayed the reverse action mode against the $C$. albicans isolate, e.g., the ergosterol content increase of app. 1.3 -fold at $16 \mu \mathrm{g} / \mathrm{mL}$ and 1.7 -fold at $4 \mu \mathrm{g} / \mathrm{mL}$ vs. the untreated control (Tables 5 and S7). Derivative $5 \mathrm{~d}$ displayed weak anti-proliferative activity against the following isolates: the C. albicans resistant to azoles and C. glabrata. HPLC analyses showed that $5 \mathrm{~d}$ at $16 \mu \mathrm{g} / \mathrm{mL}$ generated the one-fold increase in ergosterol vs. the untreated control, while the C. albicans isolate showed a decrease in ergosterol in line with the increasing concentration of compounds (Table 6).

Exposure to $6 \mathbf{a}$ or $7 \mathbf{a}$ generated a high ergosterol content at $16 \mu \mathrm{g} / \mathrm{mL}$ with the mean decrease in the total ergosterol content of app. one-fold (6a or $7 \mathbf{a}$ ) for the ref. strain vs. the untreated control. The $6 \mathbf{a}$ - or $7 \mathbf{a}$-treated clinical isolate displayed a mean decrease of one-fold (6a or 7a) compared to the untreated control (Table 5). Our SPE results of the endogenous sterol quantification (sterols decreased app. 1.2-fold at $16 \mu \mathrm{g} / \mathrm{mL}$ ) were consistent with the inhibition of cell proliferation data (SPE reading of end-point $\%=100$ in Table 2), where $\mathbf{5 d}=\mathrm{MIC}_{\mathrm{T}}$ against the SC5314 ref and the cell growth reduction $(\% \mathrm{R}=100)$ were noted. Additionally, a close agreement between the sterol quantification and broth microdilution results was seen previously by Arthington-Skaggs et al. [35]. Our HPLC results (Tables 6 and S7) of the increased endogenous ergosterol in the clinical cells treated with $\mathbf{5 d}$ at $16 \mu \mathrm{g} / \mathrm{mL}$ corresponded with Arthington-Skaggs's et al. [35] studies on azoles inducing the trailing growth phenomenon. In line with the results of Suchodolski et al. [36] for the strain displaying an uninterrupted ergosterol synthesis, we showed the highest ergosterol accumulation of an app. 0.9-fold increase in the $16 \mu \mathrm{g} / \mathrm{mL}$-treated ref. strain vs. the untreated control. Since ergosterol was a target for azoles, we showed that the ergosterol content was unsettled in the benzoxazole-treated ref. cells compared to the untreated control (Tables 5 and 6). While the way of ergosterol depletion in the $\mathbf{5 d}$ treated Candida still has to be elucidated, we clearly demonstrated that the trailing growth phenomenon classified $\mathbf{5 d}$ as active against the blastoconidial cells. Interestingly, the outcomes of our work point to the plasma membrane as a key player in the benzoxazoles' 
anti-Candida action (Figures 1-3 and S1 and Tables S8 and S9). In compliance with the studies of [37], showing that the ERG genes catalysing the late step in ergosterol synthesis were upregulated when the sterol levels were reduced, we concluded that benzoxazoles at $\mathrm{MIC}_{\mathrm{T}}(\mathbf{5 d})$ and $\mathrm{MIC}_{\mathrm{P}}(\mathbf{6} \mathbf{a}$ and $7 \mathbf{a})$ were subjected to the negative feedback regulation of the ergosterol biosynthesis [37]. We showed that the fungal cell wall is not a barrier to the action mode of benzoxazoles-inducing pyroptosis of the cells and protoplasts at a comparable percentage. Analysing ACD, no changes in susceptibility were noted for benzoxazoles that acted in spite of the cell wall presence (Figure 1) The benzoxazole mechanism was related to the weakened plasma membrane which may have lysed in the presence of MIC and subMIC conc. It was shown that the most selected active benzoxazoles induced ACD (Figure 1). Moreover, the tested compounds altered the membrane transport. As we showed (Figure 2), the accumulation of the lipophilic molecules, such as the Rho123 dye, was reduced in the $C$. albicans strains. Thus, when the benzoxazole ( $5 \mathbf{j}$ or $\mathbf{8 h}$ ) treatment was conducted, the lipophilic molecule, such as the Rho123 tracker, was reduced in the uptake and/or retention in blastoconidials. It was noted that the total conc. of Rho123 in the loading medium was higher (from 1- to 3.3-fold) than within the cells when a lower conc. of $\mathbf{5 a}, \mathbf{5 e}$, $5 \mathbf{j}$ and $8 \mathbf{h}$ was tested. Our observation demonstrated that mitochondrial respiration was affected/inhibited by the benzoxazoles $\mathbf{8} \mathbf{c}-\mathbf{d}$ and $\mathbf{8 i}$. Although, all benzoxazoles exhibited a comparably weak fungistatic effect, they showed diversity in the cell efflux inhibition. The disparity was due to the sequestration of Rho123, leading to the heterogenous sub-cellular localization [38]. The degree of intracellular sequestration was compound-dependent with $\mathbf{8} \mathbf{c}-\mathbf{d}$ and $\mathbf{8 i}$ at a higher conc., showing a stronger sequestration of $\sim 3.3$-fold vs. the lower conc. Therefore, the derivatives substituted with $\mathrm{Cl}$ or $\mathrm{Br}$ at $\mathrm{C}-4$ or trisubstituted with $\mathrm{Cl}$ at $\mathrm{C}-2,3,4$ blocked the fluorophore dye diffuse out of the sequestrating body in the blastoconidial cells. Thus, benzoxazoles could be the uptake transporter of ABCD1's substrates [39]. Thus, in line with the latter authors [39], we showed that benzoxazoles could inhibit both the passive (micelle-mediated passive diffusion) and the active process occurring via $A B C$ transporters. Moreover, benzoxazoles caused a lethal irreversibility starting with the collapse of the membrane transport through the formation of a leak (Figure 1). We monitored the cell membrane integrity using a PI transported passively into the blastoconidia. We quantified the loss of survival using flow cytometry and determining PI positivity in the benzoxazole-treated cells (Figure 1). Benzoxazole $5 \mathbf{j}$ appeared as the most effective compound inducing an efflux $\left(C_{\text {efflux }}=16 \mu \mathrm{g} / \mathrm{mL}\right.$ or $\left.1.25 \mu \mathrm{g} / \mathrm{mL}\right)$. This could have be expected, when CDR1 was overexpressed in Candida [40]. Derivative $8 \mathbf{h}$ at $\mathrm{C}_{\text {efflux }}=1.25 \mu \mathrm{g} / \mathrm{mL}$ was also the most potent inducer of the Rho123 efflux in C. albicans, although this value was app. by 4.6 -fold higher than at $0.125 \mu \mathrm{g} / \mathrm{mL}$.

The interaction with ergosterol and MIC showed that there was a specific interaction of $\mathbf{8} \mathbf{d}$ or $\mathbf{8 f}$ with ergosterol, which led to the inhibition of the cell growth (Figure 3). A PI leakage assay (Figure 1) employed in our study supported the hypothesis that benzoxazoles form pores in the fungal membrane similarly to AmB [40]. Since Itr inhibited the ergosterol synthesis and it did not form pores, the latter action mode was the case for $\mathbf{8 d}$ and $\mathbf{8 f}$. Based on our results of the ergosterol interactions and Rho123 efflux, benzoxazoles (8d and $\mathbf{8 f}$ ) induced a leakage in ergosterol even at a very high concentration $(1200 \mu \mathrm{g} / \mathrm{mL}$ in Figure 3). This indicates that benzoxazoles acted via the membrane barrier perturbation. Thus, benzoxazoles killed yeasts by permeabilizing the plasma membrane (Figure 1). Moreover, they had a similar mode of action as that of Itr inhibiting the ergosterol synthesis [41].

Based on our scaffold screening, derivatives substituted with $\mathrm{Br}$ and $\mathrm{Cl}$ facilitated the interaction with the negatively charged fungal membrane. They showed the ability to form an amphipathic secondary structure that permitted the incorporation into the outer leaflet of the bilayer of the membrane [42]. In line with Maurya et al. [42], we concluded that benzoxazoles showed a specific antifungal mechanism: an increased permeability and alterations in the cytoplasmic membrane (especially in ergosterol) without the mammalian cell toxicity (lack of ergosterol). Since the sterole-rich membrane was involved in the endo-, exocytosis and efflux, the mode of action of benzoxazoles was related to the important 
function of ergosterol in yeasts. Benzoxazoles inhibited these important processes by binding to ergosterol; thus, sterols could not perform their functional effects [43]. In line with Escalante et al. [44] and Virág et al. [45], during the interaction of $\mathbf{8 d}$ and $\mathbf{8 f}$ with ergosterol, we considered the possible formation of complexes between the carboxyl group of ergosterol and the $\mathrm{OH}$ groups of benzoxazoles (dative bounds) as well as hydrogen bounds. The activity of $\mathbf{5 a}, \mathbf{5 j}, \mathbf{8 i}$ and $\mathbf{8 c}$ (Figure S1) remained unchanged in the presence of exogenous ergosterol, suggesting that they did not interact with the membrane ergosterol.

In general, benzoxazoles can be considered as effective, safe and stable and could be used alone or in a combination therapy with AmB to treat candidiasis (including azoleresistant strains). Since the azoles' efficiency is limited by the development of Candida resistance, we introduced the benzoxazoles active against the clinical isolates resistant to azoles. We selected benzoxazoles reducing efflux pumps; thus, the increase in the number of compounds taken up by the blastoconidia resulted from changes in the ergosterol cell membrane. The intracellular accumulation of benzoxazoles was dependent on an inactive efflux of compound out of the cells. Clearly, further work needs to be undertaken to unravel benzoxazole's influence on the expression of the ATP-binding cassette (ABC) encoded by the CDR transporters and the major facilitator (MF) encoded by MDR1. Benzoxazoles based on their ergosterol biosynthesis-inhibiting capacity, membrane permeabilization activity and increased activity against the azole-resistant isolates, could be an interesting approach to address the problem of resistance. To conclude, the antifungal action of benzoxazoles and the lack of cytotoxicity as well as physico-chemical properties, e.g., good stability, water solubility, rendered $\mathbf{5 d}$ a potential candidate for the development of new antifungal drugs.

\section{Materials and Methods}

\subsection{Synthesis of Benzoxazoles}

Commercially available reagents from Sigma-Aldrich, Fluka and Avantor were used as supplied. Thin-layer chromatography was carried out on TLC aluminium plates with silica gel Kieselgel $60 \mathrm{~F}_{254}$ (Merck, Darmstadt, Germany) (0.2 mm thickness film). The column chromatography was performed using Silica gel 60 (Merck, Darmstadt, Germany) of $40-63 \mu \mathrm{m}$.

The melting points were measured with a commercial apparatus Thomas Hoover "UNI-MELT" (Thomas, Woonsocket, RI, USA) on samples placed in glass capillary tubes and were not corrected. Infrared (IR) spectra were taken on a Carl Zeiss SPECORD M80 instrument (Carl Zeiss, Jena, Germany).

The ${ }^{1} \mathrm{H}$ and ${ }^{13} \mathrm{C}$ NMR spectra were measured with a Varian 500 spectrometer (Varian, Palo Alto, CA, USA) operating at $500 \mathrm{MHz}$ for ${ }^{1} \mathrm{H}$ and $125 \mathrm{MHz}$ for ${ }^{13} \mathrm{C}$ nuclei. Chemical shifts $(\delta)$ were given in parts per million ( $\mathrm{ppm}$ ) relative to the residual solvent signal $\left(\mathrm{CDCl}_{3}, \delta_{\mathrm{H}}\right.$ of residual $\left.\mathrm{CHCl}_{3} 7.26 \mathrm{ppm}\right)$; signal multiplicity assignment: s, singlet; br s, broad singlet; d, doublet; dd, doublet of doublets; ddd, doublet of doublets of doublets; $\mathrm{m}$, multiplet. Coupling constant $(J)$ was given in hertz $(\mathrm{Hz})$. All these measurements were conducted in Warsaw University of Technology.

High-resolution mass spectrometry (HRMS) was carried out on Q Exactive Hybrid Quadrupole-Orbitrap Mass Spectrometer, ESI (electrospray) (Thermo Fisher Scientific, Bremen, Germany) with spray voltage $4.00 \mathrm{kV}$ at IBB PAS Warsaw. The most intensive signals were reported. Ketones 5-7 were synthesized according to procedures reported previously $[21,22]$.

\subsection{Synthesis of 2-amino-4-bromophenol}

To a stirred suspension of 4-bromo-2-nitrophenol (23 mmol, $5 \mathrm{~g})$ in $\mathrm{H}_{2} \mathrm{O}(30 \mathrm{~mL})$ and THF $(15 \mathrm{~mL})$, activated carbon $(9.2 \mathrm{~g})$ was added. The mixture was heated to $50-60{ }^{\circ} \mathrm{C}$, $\mathrm{NaBH}_{4}(180 \mathrm{mmol}, 6.81 \mathrm{~g})$ was added carefully in portions keeping the temperature within the range of $50-70{ }^{\circ} \mathrm{C}$ (ca 2-3 h). The reaction was carried out in $60-70{ }^{\circ} \mathrm{C}$ (typically $0.5-2 \mathrm{~h}$ ) and monitored by TLC (hexane/acetate $9 / 1 \mathrm{v} / \mathrm{v}$ ). After full conversion of bromonitrophenol, the mixture was cooled, EtOAc $(100 \mathrm{~mL})$ was added, stirring was continued overnight, 
filtered through a pad of celite, washed with EtOAc ( $100 \mathrm{~mL}$, in portions), phases were separated, the organic phase was dried $\left(\mathrm{MgSO}_{4}\right)$ and evaporated to dryness. 4-Bromo-2aminophenol was obtained as orange solid $(3.76 \mathrm{~g}$, ca $87 \%)$ and used without purification for synthesis of 5-bromo-2-mercaptobenzoxazole 2.

\subsection{Synthesis of 2-amino-4,6-dibromophenol}

According to procedure reported above, 4,6-dibromo-2-nitrophenol ( $20.2 \mathrm{mmol}, 6 \mathrm{~g})$ in suspension with $\mathrm{H}_{2} \mathrm{O}(20 \mathrm{~mL})$, THF $(10 \mathrm{~mL})$ and activated carbon $(8 \mathrm{~g})$ was reduced with $\mathrm{NaBH}_{4}$ (160 mmol, $\left.6.05 \mathrm{~g}\right)$. 4,6-Dibromo-2-aminophenol was obtained as orange solid $(4.32 \mathrm{~g}$, ca $80 \%)$ and used without purification for synthesis of 5,7-dibromo-2mercaptobenzoxazole 3 .

\subsection{General Procedure for Synthesis of Ketones 5-7}

To a stirred solution of 2-mercaptobenzoxazole 1-3 $(10 \mathrm{mmol})$ in $\mathrm{MeCN}(40 \mathrm{~mL})$ $\mathrm{K}_{2} \mathrm{CO}_{3}(15 \mathrm{mmol})$, appropriate amount of phenacyl chloride or bromide $(10 \mathrm{mmol})$ was added. The reaction was carried out at room temperature $\left(20-22^{\circ} \mathrm{C}\right)$ and monitored by TLC (hexane/acetate $9 / 1 \mathrm{v} / \mathrm{v}$ ). After full conversion of substrates (typically $1 \mathrm{~h}$, for $5 \mathbf{k} 24 \mathrm{~h}$ ), the mixture was poured on ice $(120 \mathrm{~g})$, the crude product was filtered, washed with $\mathrm{H}_{2} \mathrm{O}$ and dried on air. Ketones 5 were purified by crystallization, 6 and 7 by column chromatography. After full conversion of substrates (typically $1 \mathrm{~h}$, for $5 \mathrm{k} 24 \mathrm{~h}$ ), the mixture was poured on ice $(120 \mathrm{~g})$, the crude product was filtered, washed with water and dried on air. Crude ketones $\mathbf{5}$ were used for synthesis of alcohols $\mathbf{8}$ and purified by crystallization for biological research. Ketones 6 and 7 were purified by column chromatography (hexane/EtOAc, gradient, $50 / 0$ to $50 / 5 v / v)$.

\subsection{General Procedure for Synthesis of Alcohols 8}

To a stirred suspension of ketone $5(8 \mathrm{mmol})$ in $\mathrm{MeOH}(40 \mathrm{~mL})$ cooled to $0-2{ }^{\circ} \mathrm{C}$, $\mathrm{NaBH}_{4}(12 \mathrm{mmol})$ was added in portions keeping the temperature below $2-3{ }^{\circ} \mathrm{C}(\mathrm{ca} 0.5 \mathrm{~h})$. The reaction was carried out at $0-2{ }^{\circ} \mathrm{C}$ and monitored by TLC (hexane/acetate $5 / 1 \mathrm{v} / \mathrm{v}$ ). After full conversion of ketone 5 (typically $1-3 \mathrm{~h}$ ), the mixture was poured on ice $(120 \mathrm{~g}$ ). Solid products $(\mathbf{8 b}, \mathbf{c}, \mathbf{d}, \mathbf{i})$ were filtered and washed with $\mathrm{H}_{2} \mathrm{O}$. Oily products were extracted with EtOAc $(3 \times 50 \mathrm{~mL})$, washed with $\mathrm{H}_{2} \mathrm{O}(5 \times 50 \mathrm{~mL})$, dried $\left(\mathrm{MgSO}_{4}\right)$, filtered and evaporated. Alcohols 8 were purified by crystallization (hexane/EtOAc $10 / 1 v / v$ ) or by column chromatography (hexane/EtOAc, gradient, 50/0 to 50/5 v/v).

\subsection{Fungal Strains and Culture Conditions}

Antifungal activity of benzoxazole derivatives was tested against the reference Candida albicans SC5314 strain from American Type Culture Collection (ATCC). Additionally, two clinical isolates were used in biological activity testing: C. albicans (fluconazole- and itraconazole-resistant) and C. glabrata. The strains were stored at $-80{ }^{\circ} \mathrm{C}$ in Microbank system (Pro-Lab Diagnostics, Round Rock, TX, USA). Prior to biological examinations, yeasts were cultured overnight in YEPD (Yeast Extract Peptone Dextrose) or in RPMI 1640 (Roswell Park Memorial Institute, NY, Buffalo, USA) at $30{ }^{\circ} \mathrm{C}$ with shaking at $100 \mathrm{rpm}$. Then, cells were harvested at 3,000 rpm for $5 \mathrm{~min}$ at $4{ }^{\circ} \mathrm{C}$ and washed twice with sterile water. The final inoculum ranged from $1.9 \times 10^{7}$ to $4.0 \times 10^{8} \mathrm{CFU} / \mathrm{mL}$.

\subsection{In Vitro Antifungal Activity}

Antifungal activity was assessed using broth microdilution assay according to the reference CLSI (Clinical and Laboratory Standards Institute) M27-A3 method [13,28,46]. Stock solution of compounds $(1600 \mu \mathrm{g} / \mathrm{mL})$ was prepared in $96 \%$ DMSO. Initial inoculum was $10^{5}$-fold diluted in sterile water and then 1:20 in a medium. Sets of compound test wells (CTW) and sterility control wells (SCW) were prepared in 96-well plates in triplicate for each conc. containing the tested compounds and inoculum (CTW) or sterile water instead of inoculum (SCW) in YEPD or RPMI 1640 medium. Growth control wells (GCW) with 
inoculum and DMSO (the same amount as in the CTW/SCW wells) in suitable medium were prepared. Plates were incubated for $18 \mathrm{~h}$ at $30^{\circ} \mathrm{C}$ and evaluated using Synergy H4 Hybrid Reader (BioTek Instruments, Winooski, VT, USA) or with Spark Control M10 (Tecan Group, Männedorf, Switzerland) at $405 \mathrm{~nm}$. Percentage of cell growth inhibition was calculated as follows: $\%$ of inhibition $=100 \times\left(1-\left(\mathrm{OD}_{\mathrm{CTW}}-\mathrm{OD}_{\mathrm{SCW}}\right) /\left(\mathrm{OD}_{\mathrm{GCW}}-\mathrm{OD}_{\mathrm{SCW}}\right)\right.$. MIC (Minimum Inhibitory Concentration) was determined as the lowest concentration in which a prominent decrease in growth was visible according to the standard criteria from CLSI [28].

\subsection{Cytotoxicity Assay In Vitro}

Cytotoxicity of $\mathbf{5 d}, \mathbf{6 a}$ and $\mathbf{7 a}$ was assessed against mammal Vero cell line (ATCC CCL-81, LGC Standards, Poland) using MTS test (3-(4.5-dimethylthiazol-2-yl)-5-(3carboxymethoxyphenyl)-2-(4-sulfophenyl)-2H-tetrazolium, MTS, Promega, USA) and for $\mathbf{5 a}, \mathbf{5 e}, \mathbf{5 j}, \mathbf{8 c}, \mathbf{8 d}, \mathbf{8 h}$, and $\mathbf{8 i}$ against mammal MRC-5 cell line (ATCC CCL-171) by MTT assay (3-(4.5-dimethylthiazol-2-yl)-2.5-diphenyltetrazolium bromide, MTT, Thermo Fisher Scientific, USA) [47,48]. Vero and MRC-5 cell lines were maintained in EMEM (Eagle's Minimum Essential Medium (Merck SA, Darmstadt, Germany) supplemented with 10\% FBS (foetal bovine serum, Gibco, Thermo Fisher Scientific, Dublin, Irlandia) and 1\% antibiotics at $37^{\circ} \mathrm{C}$ and $5 \% \mathrm{CO}_{2}$. Cells were incubated in 96-well microtiter plates for $24 \mathrm{~h}$. Vero and MRC- 5 cell monolayers were treated with different conc. of the benzoxazoles. Following $10 \mu \mathrm{L}$ of MTS or MTT, reagents were added to each well and then each plate was incubated for $3 \mathrm{~h}$ in darkness.

The optical densities were measured at $490 \mathrm{~nm}$ (for MTS assay) and $495 \mathrm{~nm}$ (for MTT assay) with $660 \mathrm{~nm}$ as the reference wavelength using Synergy H4 Hybrid Reader (BioTek Instruments, Winooski, VT, USA) or Spark Control M10 (Tecan Group, Männedorf, Switzerland). Specific absorbance (SA) was calculated using the following formula: $\mathrm{SA}=\mathrm{A}_{490 / 495}-\mathrm{A}_{660}$. The cytotoxicity was calculated using the following formula: $\%$ cytotoxicity $=($ SA Positive control - SA Test $) /($ SA Positive control - SA Blank $) \times 100$. Positive control means Vero or MCR-5 monolayer in EMEM and Blank means EMEM with tested conc. of compounds [31].

\subsection{Ergosterol Estimation Assay Using Spectrophotometry and HPLC}

Extraction of ergosterol was performed as previously described in literature with slight modifications [49]. Samples containing $0.5 \mathrm{~mL}$ of initial inoculum and tested compound (or no compound in growth controls) in YEPD (final volume $5 \mathrm{~mL}$ ) were incubated for $24 \mathrm{~h}$ at $30^{\circ} \mathrm{C}$ with shaking at $100 \mathrm{rpm}$. Cells were harvested using $3000 \mathrm{rpm}$ for $5 \mathrm{~min}$ at $4{ }^{\circ} \mathrm{C}$ and washed with sterile water. The wet weight of the cell pellet was determined at the range of $0.04-0.09 \mathrm{~g}$. Then, saponification was performed as follows: $3 \mathrm{~mL}$ of $25 \%$ alcoholic potassium hydroxide solution was added to each sample and mixed. Cell suspensions were incubated for $1 \mathrm{~h}$ at $85^{\circ} \mathrm{C}$ in a water bath. Samples were then left to cool at room temp. Ergosterol was extracted by addition of $1 \mathrm{~mL}$ of sterile water and $3 \mathrm{~mL}$ of petroleum ether followed by vortex mixing. Organic layers were transferred to different tubes. For spectrophotometric analysis, organic layers were diluted five times with ethanol and then analysed using scanned spectrophotometry between 230 and $300 \mathrm{~nm}$ with Synergy H4 Hybrid Reader (BioTek Instruments, Winooski, VT, USA). Ergosterol content was calculated using the sum of ergosterol and 24(28)-dehydroergosterol (DHE. late sterol intermediate) according to the formulas [49,50]: \%ergosterol $+\% \mathrm{DHE}=\left(\mathrm{A}_{282} \times 5 / 290\right) /$ pellet weight $(\mathrm{g})$; $\%$ DHE $=\left(\mathrm{A}_{230} \times 5 / 518\right) /$ pellet weight $(\mathrm{g}) ; \%$ ergosterol $=(\%$ ergosterol $+\% \mathrm{DHE})-\% \mathrm{DHE}$.

For quantification of ergosterol by HPLC, organic solvent was evaporated. Sterols were re-dissolved in methanol (HPLC grade) and stored at $4{ }^{\circ} \mathrm{C}$. HPLC analysis were performed using 200 Series Nelson NCI 900 system with UV/VIS detection at $282 \mathrm{~nm}$ (PerkinElmer, Waltham, MA, USA) and COSMOSIL C18-MS-II column (Nacalai Tesque, Kyoto, Japan). Gradient elusion was performed starting with acetonitrile: methanol 97:3 $v / v$ as the mobile phase. 


\subsection{Cytometric Analysis of C. albicans Cell Death Type}

Protoplasts of C. albicans SC5314 were prepared following the method described in previous article [51]. Cells and protoplasts were treated with $\mathbf{5 d}, \mathbf{6 a}$ and $\mathbf{7 a}$ at conc. of 16 or $4 \mu \mathrm{g} / \mathrm{mL}$ with shaking at $200 \mathrm{rpm}$ at $30^{\circ} \mathrm{C}$ for $24 \mathrm{~h}$ and cells were treated with the following derivatives: $\mathbf{5 e}, \mathbf{5 a}, \mathbf{5 j}, \mathbf{8 h}, \mathbf{8 c}, \mathbf{8 i}, \mathbf{8 d}$ and $\mathbf{8 f}$ at $16 \mu \mathrm{g} / \mathrm{mL}$ for $24 \mathrm{~h}$. After centrifugation at $3000 \mathrm{rpm}$ at $4{ }^{\circ} \mathrm{C}$ for $5 \mathrm{~min}$, the cells were washed and resuspended in sterile water. Staining was preformed according to the annexin and propidium iodide staining kit's procedure (FITC Annexin V/Dead Cell Apoptosis Kit with FITC annexin V and PI for flow cytometry (Invitrogen, Thermo Fisher Scientific, Dublin, Irlandia) [52]. Suspensions were 10 times diluted in suitable buffer (Invitrogen, Thermo Fisher Scientific, Dublin, Irlandia). Then, $1 \mu \mathrm{L}$ of annexin was added, mixed and after $15 \mathrm{~min}$ of incubation on ice, the cells and protoplasts were centrifuged at $6000 \mathrm{rpm}$ and $4{ }^{\circ} \mathrm{C}$ for $5 \mathrm{~min}$ and resuspended in buffer. Then, $1 \mu \mathrm{L}$ of PI was added and after $15 \mathrm{~min}$ incubation in ice, fluorescence was measured by flow cytometry with BD FACSLyric 2L6C (BD Biosciences, Franklin Lakes, NJ, USA) for the compounds $\mathbf{5 d}, \mathbf{6 a}$ and $\mathbf{7 a}$, and with FACSCanto II (Becton Dickinson, National Institute of Drugs, Warsaw, Poland) for $\mathbf{5 e}, \mathbf{5 a}, 5 \mathbf{j}, \mathbf{8 h}, \mathbf{8 c}, \mathbf{8 i}, \mathbf{8 d}$ and $\mathbf{8 f}$. Data were analysed with FACSuite Software 1.4 RUO (BD Biosciences, Franklin Lakes, NJ, USA).

\subsection{Examination of Rhodamine 123 Efflux in the C. albicans SC5314 Treated with Benzoxazole Derivatives}

Procedure was based on the protocol in Gbelska's article [53,54]. C. albicans SC5314 cells were added to YEPD medium and incubated at $28^{\circ} \mathrm{C}$ for $20 \mathrm{~h}$ with shaking at $150 \mathrm{rpm}$. Cells were then washed with water and PBS/ $\mathrm{NaOH}$. Two microliters of 2-deoxy-D-glucose and Rhodamine123 (Rho123) both at $20 \mathrm{mM}$ were added to $1 \mathrm{~mL}$ of the cell suspended in PBS for each tested compound (5e, 5a, 5j, $\mathbf{8 h}, \mathbf{8 c}, \mathbf{8 i}, \mathbf{8 d})$. After $18 \mathrm{~h}$ incubation at $28^{\circ} \mathrm{C}$ and $150 \mathrm{rpm}$, suspensions were centrifuged and cells were washed with water and PBS. Tested compounds were added to final conc. Of 0.125 or $1.25 \mu \mathrm{g} / \mathrm{mL}(\mathbf{5 j}, \mathbf{8 h}, \mathbf{8 i})$ and 16 or $160 \mu \mathrm{g} / \mathrm{mL}(\mathbf{5 e}, \mathbf{5 a}, \mathbf{8 c}, \mathbf{8 d})$. Then, $200 \mu \mathrm{L}$ of $20 \mathrm{mM}$ glucose were then added to cells and after $18 \mathrm{~h}$ incubation at $28^{\circ} \mathrm{C}$ with shaking at $150 \mathrm{rpm}, 100 \mu \mathrm{L}$ of supernatant was placed into 96-well plate. Fluorescence of Rho123 was examined with excitation at $521 \mathrm{~nm}$ and emission at $600 \mathrm{~nm}$ using plate reader Spark Control M10 (Tecan Group, Männedorf, Switzerland).

\subsection{Antifungal Studies Using Exogenous Ergosterol}

To test compounds' affinity to ergosterol, their antifungal activities in the presence of exogenous ergosterol were examined. Ergosterol (Sigma-Aldrich, Saint Louis, MO, USA) was dissolved in $96 \%$ DMSO and Triton X-100 or Tween 20 (to final volumes of $10 \%$ and $1 \%$, respectively) [55]. Emulsion was heated, mixed and added to the medium. A 96-well plate was prepared analogically to the reference broth microdilution CLSI M27-A3 method [28]. Compound test wells (CTW) containing C. albicans SC5314 inoculum and separately the following compounds: $\mathbf{5 a}, \mathbf{5 e}, \mathbf{5 j}, \mathbf{8 c}, \mathbf{8 d}, \mathbf{8 f}, \mathbf{8 h}, \mathbf{8} \mathbf{i}$, exogenous ergosterol in YPD or RPMI 1640 medium were prepared in triplicates. Sterility control wells (SCW) contained tested compounds and ergosterol in medium. The growth control wells (GCW) contained inoculum, DMSO and ergosterol suspended in medium. Final concentration of exogenous ergosterol in each well was $400 \mu \mathrm{g} / \mathrm{mL}$. Additionally, for examination antifungal activity of $\mathbf{5 a}, \mathbf{5 e}, \mathbf{5 j}, \mathbf{8 c}, \mathbf{8 d}, \mathbf{8 f}, \mathbf{8 h}, \mathbf{8 i}$, wells containing inoculum, ergosterol and itraconazole ITR (Sigma-Aldrich, Saint Louis, MO, USA) in medium (instead of tested derivatives) were prepared. Plates were incubated at $30^{\circ} \mathrm{C}$ for $18-96 \mathrm{~h}$ and analysed using Synergy H4 Hybrid Reader (BioTek Instruments, Winooski, VT, USA) or with Spark Control M10 (Tecan Group, Männedorf, Switzerland) at 400 or $405 \mathrm{~nm}$. 
4.13. Determination of Antifungal Effect of Benzoxazole Derivatives Combined with Amphotericin $B(A m B)$. FIC Index Calculation

To determine Fractional Inhibitory Concentration (FIC) index between $\mathbf{5 d}$ and AmB, a modification of checkerboard microdilution method was performed analogically to the CLSI M27-A3 method described above [28]. Compound test wells (CTW) contained as follows: AmB $(250 \mu \mathrm{g} / \mathrm{mL}$; Sigma-Aldrich. USA) (conc. ranging from $2.5 \mu \mathrm{g} / \mathrm{mL}$ to $0.0049 \mu \mathrm{g} / \mathrm{mL})$ and $5 \mathrm{~d}(16-0.25 \mu \mathrm{g} / \mathrm{mL})$ or combination of these two compounds. GCW and SCW wells were prepared as described above in CLSI [28]. Samples were placed in 96-well plate and incubated at $30{ }^{\circ} \mathrm{C}$ for $96 \mathrm{~h}$. Growth inhibition rate was measured at $405 \mathrm{~nm}$ and percentage of cell growth inhibition in each well was calculated. The FIC index was determined using the formula as follows: $\mathrm{FIC}=\mathrm{C}(\mathbf{5 d}) / \mathrm{MIC}(5 \mathbf{d})+\mathrm{C}(\mathrm{AmB}) / \mathrm{MIC}(\mathrm{AmB})$, where MIC of $\mathbf{5 d}$ or AmB and C stands for conc. of $\mathbf{5 d}$ or AmB in well containing combination of two compounds resulting in at least $50 \%$ growth inhibition in a given well in the 96-well microtiter plate in spectrophotometric (SPE) method [56]. Interactions were categorized according to the method of [32] by the following rules: synergism $(\mathrm{FIC}, \leq 0.5)$, additivity (FIC, $>0.5$ to $\leq 1$ ) and indifference (FIC, $>1$ to $<4$ ).

\subsection{Statistical Analysis}

All experiments were performed in triplicate. Data were represented as mean $\pm \mathrm{SD}$. Statistically significant differences ( $p$ values $\leq 0.05$ ) between the control and test values were determined by means of the Wilcoxon-signed rank-matched pair test using SPSS 16.0 software (Spss 16.0 free download). Moreover, the method comparison studies were determined by the means of regression and Pearson correlation coefficient.

Supplementary Materials: The following are available online. Figure S1: Interaction between benzoxazoles and ergosterol, Table S1: Antifungal activity of benzoxazole derivatives against $C$. albicans ATCC SC5314, Table S2. Antifungal activity of benzoxazole derivatives against C. albicans ATCC SC5314, Table S3. Antifungal activity of benzoxazole derivatives against the C. albicans clinical strain, Table S4. Antifungal activity of benzoxazole derivatives against the C. glabrata clinical strain, Table S5. Viability of the Vero cells-treated with benzoxazole derivatives, Table S6. Viability of the MRC- 5 cells (mean $\% \pm$ SD) treated with benzoxazole derivatives, Table S7. Ergosterol content measured by HPLC in C. albicans ATCC SC5314 treated with benzoxazole derivatives compared to the growth control, Table S8. Fraction of the C. albicans ATCC SC5314 cells in accidental cell death (ACD) caused by treatment with benzoxazole derivatives. Table S9. Rho123 efflux in cells treated with benzoxazoles in the MIC's and sub-MIC's concentrations.

Author Contributions: Conceptualization, M.S. and A.K.; methodology, M.S.; software, J.B.; validation, M.S., A.K., E.Ł.-C. and Ł.K.; formal analysis, M.S.; investigation, A.G. and J.K.; resources, J.K.; data curation, J.K.; writing — original draft preparation, M.S. and J.K.; writing — review and editing, M.S.; visualization, M.R. and A.G.; supervision, M.S. and Ł.K.; project administration, M.S.; funding acquisition, M.S. All authors have read and agreed to the published version of the manuscript.

Funding: M. Staniszewska was financed by the Centre for Advanced Materials and Technologies CEZAMAT, Warsaw University of Technology, Poland. Ł. Kuryk was supported by the grant (BW-3/2021 and 1BWBW/2021) funded by the National Institute of Public Health (NIH)-National Research Institute (NIPH NIH-NRI), Poland. M. Rogalska, Aleksander Gryciuk, Joanna Kawalec and J. Baran were supported by the Faculty of Chemistry, Warsaw University of Technology, Poland. E. Łukowska-Chojnacka and A. Kowalkowska were supported by the Faculty of Chemistry, Warsaw University of Technology, Poland.

Institutional Review Board Statement: Not applicable.

Informed Consent Statement: Not applicable.

Data Availability Statement: Not applicable.

Conflicts of Interest: The authors declare no conflict of interest. The funders had no role in the design of the study; in the collection, analyses, or interpretation of data; in the writing of the manuscript, or in the decision to publish the results. 
Sample Availability: There is no sample availability.

\section{References}

1. De Oliveira Filho, A.A.; de Oliveira, H.M.B.F.; de Sousa, J.P.; Meireles, D.R.P.; de Azevedo Maia, G.L.; Filho, J.M.B.; de Siqueira Júnior, J.P.; Lima, E.O. In vitro anti-Candida activity and mechanism of action of the flavonoid isolated from Praxelis clematidea against Candida albicans species. J. Appl. Pharm. Sci. 2016, 6, 066-069. [CrossRef]

2. Sattar, R.; Mukhtar, R.; Atif, M.; Hasnain, M.; Irfan, A. Synthetic transformations and biological screening of benzoxazole derivatives: A review. J. Heterocycl. Chem. 2020, 57, 2079-2107. [CrossRef]

3. Luo, B.; Li, D.; Zhang, A.L.; Gao, J.M. Synthesis, antifungal activities and molecular docking studies of benzoxazole and benzothiazole derivatives. Molecules 2018, 23, 2457. [CrossRef] [PubMed]

4. Kakkar, S.; Kumar, S.; Narasimhan, B.; Lim, S.M.; Ramasamy, K.; Mani, V.; Shah, S.A.A. Design, synthesis and biological potential of heterocyclic benzoxazole scaffolds as promising antimicrobial and anticancer agents. Chem. Cent. J. 2018, 12, 1-11. [CrossRef] [PubMed]

5. Singh, S.; Veeraswamy, G.; Bhattarai, D.; Goo, J., II; Lee, K.; Choi, Y. Recent Advances in the Development of Pharmacologically Active Compounds that Contain a Benzoxazole Scaffold. Asian J. Org. Chem. 2015, 4, 1338-1361. [CrossRef]

6. Kakkar, S.; Tahlan, S.; Lim, S.M.; Ramasamy, K.; Mani, V.; Shah, S.A.A.; Narasimhan, B. Benzoxazole derivatives: Design, synthesis and biological evaluation. Chem. Cent. J. 2018, 12, 1-16. [CrossRef]

7. Erol, M.; Celik, I.; Uzunhisarcikli, E.; Kuyucuklu, G. Synthesis, Molecular Docking, and DFT Studies of Some New 2,5-Disubstituted Benzoxazoles as Potential Antimicrobial and Cytotoxic Agents. Polycycl. Aromat. Compd. 2020, 1-18. [CrossRef]

8. De Carvalho, L.I.S.; Alvarenga, D.J.; Do Carmo, L.C.F.; De Oliveira, L.G.; Silva, N.C.; Dias, A.L.T.; Coelho, L.F.L.; De Souza, T.B.; Dias, D.F.; Carvalho, D.T. Antifungal Activity of New Eugenol-Benzoxazole Hybrids against Candida spp. J. Chem. 2017, 2017. [CrossRef]

9. Zomorodian, K.; Khabnadideh, S.; Sakhteman, A.; Mirjalili, B.B.F.; Ranjbar, M.; Zamani, L. Synthesis and antifungal activity of benzoxazole derivatives with their sar analysis by SAS-MAP. Farmacia 2020, 68, 155-163. [CrossRef]

10. Padalkar, V.S.; Borse, B.N.; Gupta, V.D.; Phatangare, K.R.; Patil, V.S.; Umape, P.G.; Sekar, N. Synthesis and antimicrobial activity of novel 2-substituted benzimidazole, benzoxazole and benzothiazole derivatives. Arab. J. Chem. 2016, 9, S1125-S1130. [CrossRef]

11. Kuroyanagi, J.I.; Kanai, K.; Sugimoto, Y.; Horiuchi, T.; Achiwa, I.; Takeshita, H.; Kawakami, K. 1,3-Benzoxazole-4-carbonitrile as a novel antifungal scaffold of $\beta-1,6$-glucan synthesis inhibitors. Bioorg. Med. Chem. 2010, 18, 7593-7606. [CrossRef]

12. Jayanna, N.D.; Vagdevi, H.M.; Dharshan, J.C.; Raghavendra, R.; Telkar, S.B. Synthesis, antimicrobial, analgesic activity, and molecular docking studies of novel 1-(5,7-dichloro-1,3-benzoxazol-2-yl)-3-phenyl-1H-pyrazole-4-carbaldehyde derivatives. Med. Chem. Res. 2013, 22, 5814-5822. [CrossRef]

13. Łukowska-Chojnacka, E.; Mierzejewska, J.; Milner-Krawczyk, M.; Bondaryk, M.; Staniszewska, M. Synthesis of novel tetrazole derivatives and evaluation of their antifungal activity. Bioorg. Med. Chem. 2016, 24, 6058-6065. [CrossRef]

14. Özdemir, A.; Turan-Zitouni, G.; Asim Kaplancikli, Z.; Revial, G.; Demirci, F.; Isscan, G. Preparation of some pyrazoline derivatives and evaluation of their antifungal activities. J. Enzym. Inhib. Med. Chem. 2010, 25, 565-571. [CrossRef]

15. Kaplancikli, Z.A.; Yurttaş, L.; Özdemir, A.; Turan-Zitouni, G.; Işcan, G.; Akalin, G.; Abu Mohsen, U. Synthesis, anticandidal activity and cytotoxicity of some tetrazole derivatives. J. Enzym. Inhib. Med. Chem. 2014, 29, 43-48. [CrossRef] [PubMed]

16. Karaburun, A.Ç.; Çevik, U.A.; Osmaniye, D.; Saglık, B.N.; Çavuşoglu, B.K.; Levent, S.; Özkay, Y.; Koparal, A.S.; Behçet, M.; Asım Kaplanciklı, Z. Synthesis and evaluation of new 1,3,4-thiadiazole derivatives as potent antifungal agents. Molecules 2018, 23, 3129. [CrossRef] [PubMed]

17. Kaplancikli, Z.A. Synthesis of some oxadiazole derivatives as new anticandidal agents. Molecules 2011, 16, 7662-7671. [CrossRef]

18. El-Gohary, N.S.; Shaaban, M.I. Synthesis, antimicrobial, antiquorum-sensing and antitumor activities of new benzimidazole analogs. Eur. J. Med. Chem. 2017, 137, 439-449. [CrossRef] [PubMed]

19. Karaca Gençer, H.; Acar Çevik, U.; Levent, S.; Sağlık, B.N.; Korkut, B.; Özkay, Y.; Ilgın, S.; Öztürk, Y. New Benzimidazole-1,2,4Triazole Hybrid Compounds: Synthesis, Anticandidal Activity and Cytotoxicity Evaluation. Molecules 2017, 22, 507. [CrossRef] [PubMed]

20. Yurttaş, L.; Duran, M.; Demirayak, Ş.; Gençer, H.K.; Tunali, Y. Synthesis and initial biological evaluation of substituted 1-phenylamino-2-thio-4,5-dimethyl-1H-imidazole derivatives. Bioorg. Med. Chem. Lett. 2013, 23, 6764-6768. [CrossRef] [PubMed]

21. Łukowska-Chojnacka, E.; Kowalkowska, A.; Napiórkowska, A. Lipase-catalyzed kinetic resolution of novel antitubercular benzoxazole derivatives. Chirality 2018, 30, 457-468. [CrossRef]

22. Zeynizadeh, B.; Setamdideh, D. NaBH4/charcoal: A new synthetic method for mild and convenient reduction of nitroarenes Synth. Commun. 2006, 36, 2699-2704. [CrossRef]

23. Yamada, N.; Mizuochi, M.; Takeda, M.; Kawaguchi, H.; Morita, H. A facile and efficient one-pot synthesis of thiirans by the reaction of benzoxazolyl $\beta$-ketosulfides with $\mathrm{NaBH} 4 / \mathrm{NaOH}$. Tetrahedron Lett. 2008, 49, 1166-1168. [CrossRef]

24. Loghmani-Khouzani, H.; Hajiheidari, D. Synthesis of difluorinated $\beta$-ketosulfones and novel gem-difluoromethylsulfonecontaining heterocycles as fluorinated building blocks. J. Fluor. Chem. 2010, 131, 561-569. [CrossRef]

25. Varun, B.V.; Gadde, K.; Prabhu, K.R. Synthesis of $\alpha$-sulfenyl monoketones: Via a metal-free oxidative cross dehydrogenative coupling (CDC) reaction. Org. Biomol. Chem. 2016, 14, 7665-7670. [CrossRef] 
26. Yang, Z.; Li, J.; Hua, J.; Yang, T.; Yi, J.; Zhou, C. KI/ $\mathrm{K}_{2} \mathrm{~S}_{2} \mathrm{O}_{8}$-Mediated $\alpha-\mathrm{C}-\mathrm{H}$ Sulfenylation of Carbonyl Compounds with (Hetero)Aryl Thiols. Synlett 2017, 28, 2325-2329. [CrossRef]

27. Md. Khaja Mohinuddin, P.; Gangi Reddy, N.C. Zinc oxide catalyzed solvent-free mechanochemical route for C-S bond construction: A sustainable process. Eur. J. Org. Chem. 2017, 2017, 1207-1214. [CrossRef]

28. Clinical and Laboratory Standards Institute (CLSI). Reference Method for Broth Dilution Antifungal Susceptibility Testing of Yeasts, 3rd ed.; Clinical and Laboratory Standards Institute: Wayne, PA, USA, 2008.

29. Menezes, C.; Valerio, E.; Dias, E. The Kidney Vero-E6 Cell Line: A Suitable Model to Study the Toxicity of Microcystins. N. Insights Toxic. Drug Test. 2013. [CrossRef]

30. Abdi Goushbolagh, N.; Farhood, B.; Astani, A.; Nikfarjam, A.; Kalantari, M.; Zare, M.H. Quantitative Cytotoxicity, Cellular Uptake and Radioprotection Effect of Cerium Oxide Nanoparticles in MRC-5 Normal Cells and MCF-7 Cancerous Cells. BioNanoScience 2018, 8, 769-777. [CrossRef]

31. Staniszewska, M.; Sobiepanek, A.; Małgorzata, G.; Peña-Cabrera, E.; Arroyo-Córdoba, I.J.; Michalina, K.; Kuryk, Ł.; Wieczorek, M.; Koronkiewicz, M.; Kobiela, T.; et al. Sulfone derivatives enter the cytoplasm of Candida albicans sessile cells. Eur. J. Med. Chem. 2020, 191. [CrossRef]

32. Te Dorsthorst, D.T.A.; Verweij, P.E.; Meis, J.F.G.M.; Punt, N.C.; Mouton, J.W. Comparison of fractional inhibitory concentration index with response surface modeling for characterization of in vitro interaction of antifungals against itraconazole-susceptible and -resistant Aspergillus fumigatus isolates. Antimicrob. Agents Chemother. 2002, 46, 702-707. [CrossRef]

33. Whaley, S.G.; Berkow, E.L.; Rybak, J.M.; Nishimoto, A.T.; Barker, K.S.; Rogers, P.D. Azole antifungal resistance in Candida albicans and emerging non-albicans Candida Species. Front. Microbiol. 2017, 7, 1-12. [CrossRef]

34. Al-Harthy, T.; Zoghaib, W.; Abdel-Jalil, R. Importance of fluorine in benzazole compounds. Molecules 2020, 25, 4677. [CrossRef] [PubMed]

35. Arthington-Skaggs, B.A.; Lee-Yang, W.; Ciblak, M.A.; Frade, J.P.; Brandt, M.E.; Hajjeh, R.A.; Harrison, L.H.; Sofair, A.N.; Warnock, D.W. Comparison of visual and spectrophotometric methods of broth microdilution MIC end point determination and evaluation of a sterol quantitation method for in vitro susceptibility testing of fluconazole and itraconazole against trailing and nontrailing Cand. Antimicrob. Agents Chemother. 2002, 46, 2477-2481. [CrossRef]

36. Suchodolski, J.; Muraszko, J.; Bernat, P.; Krasowska, A. A crucial role for ergosterol in plasma membrane composition, localisation, and activity of Cdr1p and $\mathrm{H}^{+}$-ATPase in Candida albicans. Microorganisms 2019, 7, 378. [CrossRef] [PubMed]

37. Li, H.; Gong, H.; Qi, Y.; Li, J.; Ji, X.; Sun, J.; Tian, R.; Bao, H.; Song, X.; Chen, Q.; et al. In vitro and in vivo antifungal activities and mechanism of heteropolytungstates against Candida species. Sci. Rep. 2017, 7, 1-9. [CrossRef]

38. Yumoto, R.; Murakami, T.; Sanemasa, M.; Nasu, R.; Nagai, J.; Takano, M. Pharmacokinetic interaction of cytochrome P450 3A-related compounds with rhodamine 123, a P-glycoprotein substrate, in rats pretreated with dexamethasone. Drug Metab. Dispos. 2001, 29, 145-151. [PubMed]

39. Forster, S.; Thumser, A.E.; Hood, S.R.; Plant, N. Characterization of rhodamine-123 as a tracer dye for use in in vitro drug transport assays. PLoS ONE 2012, 7. [CrossRef]

40. Ramsdale, M. Programmed cell death in pathogenic fungi. Biochim. Biophys. Acta Mol. Cell Res. 2008, 1783, 1369-1380. [CrossRef] [PubMed]

41. François, I.E.J.A.; Cammue, B.P.A.; Borgers, M.; Ausma, J.; Dispersyn, G.D.; Thevissen, K. Azoles: Mode of antifungal action and resistance development. Effect of miconazole on endogenous reactive oxygen species production in Candida albicans. Anti-Infect. Agents Med. Chem. 2006, 5, 3-13. [CrossRef]

42. Maurya, I.K.; Thota, C.K.; Sharma, J.; Tupe, S.G.; Chaudhary, P.; Singh, M.K.; Thakur, I.S.; Deshpande, M.; Prasad, R.; Chauhan, V.S. Mechanism of action of novel synthetic dodecapeptides against Candida albicans. Biochim. Biophys. Acta-Gen. Subj. 2013, 1830, 5193-5203. [CrossRef]

43. Te Welscher, Y.M.; Ten Napel, H.H.; Balagué, M.M.; Souza, C.M.; Riezman, H.; De Kruijff, B.; Breukink, E. Natamycin blocks fungal growth by binding specifically to ergosterol without permeabilizing the membrane. J. Biol. Chem. 2008, 283, 6393-6401. [CrossRef]

44. Escalante, A.; Gattuso, M.; Pérez, P.; Zacchino, S. Evidence for the mechanism of action of the antifungal phytolaccoside B isolated from Phytolacca tetramera Hauman. J. Nat. Prod. 2008, 71, 1720-1725. [CrossRef] [PubMed]

45. Virág, E.; Pesti, M.; Kunsági-Máté, S. Complex formation between primycin and ergosterol: Entropy-driven initiation of modification of the fungal plasma membrane structure. J. Antibiot. 2012, 65, 193-196. [CrossRef] [PubMed]

46. Staniszewska, M.; Bondaryk, M.; Wieczorek, M.; Estrada-Mata, E.; Mora-Montes, H.M.; Ochal, Z. Antifungal effect of novel 2-bromo-2-chloro-2-(4-chlorophenylsulfonyl)-1-phenylethanone against Candida Strains. Front. Microbiol. 2016, 7. [CrossRef]

47. Promega CellTiter 96 AQueous One Solution Cell Proliferation Assay. Available online: http://www.promega.com (accessed on 14 June 2021).

48. Thermofisher Scientific CyQUANTTM MTT Cell Proliferation Assay Kit. Available online: http://www.thermofisher.com (accessed on 14 June 2021).

49. Singh, S.; Fatima, Z.; Hameed, S. Octyl gallate reduces ABC multidrug transporter CaCdr1p expression and leads to its mislocalisation in azole-resistant clinical isolates of Candida albicans. J. Glob. Antimicrob. Resist. 2020, 22, 497-503. [CrossRef]

50. Tian, J.; Ban, X.; Zeng, H.; He, J.; Chen, Y.; Wang, Y. The mechanism of antifungal action of essential oil from dill (Anethum graveolens 1.) on Aspergillus flavus. PLoS ONE 2012, 7. [CrossRef] 
51. Borowiecki, P.; Wińska, P.; Bretner, M.; Gizińska, M.; Koronkiewicz, M.; Staniszewska, M. Synthesis of novel proxyphylline derivatives with dual Anti-Candida albicans and anticancer activity. Eur. J. Med. Chem. 2018, 150, 307-333. [CrossRef]

52. Invitrogen FITC Annexin V/Dead Cell Apoptosis Kit with FITC annexin V and PI, for Flow Cytometry. Available online: http: / / www.thermofisher.com (accessed on 14 June 2021).

53. Gbelska, Y.; Toth Hervay, N.; Dzugasova, V.; Konecna, A. Measurement of Energy-dependent Rhodamine 6G Efflux in Yeast Species. Bio Protoc. 2017, 7. [CrossRef]

54. Zielinska, P.; Staniszewska, M.; Bondaryk, M.; Koronkiewicz, M.; Urbanczyk-Lipkowska, Z. Design and studies of multiple mechanism of anti-Candida activity of a new potent Trp-rich peptide dendrimers. Eur. J. Med. Chem. 2015, 105, 106-119. [CrossRef] [PubMed]

55. Leite, M.C.A.; De Brito Bezerra, A.P.; De Sousa, J.P.; Guerra, F.Q.S.; De Oliveira Lima, E. Evaluation of antifungal activity and mechanism of action of citral against Candida albicans. Evid. Based Complement. Altern. Med. 2014, 2014. [CrossRef] [PubMed]

56. Vale-Silva, L.; Ischer, F.; Leibundgut-Landmann, S.; Sanglard, D. Gain-of-function mutations in PDR1, a regulator of antifungal drug resistance in candida glabrata, control adherence to host cells. Infect. Immun. 2013, 81, 1709-1720. [CrossRef] [PubMed] 